\title{
Atlantic-Pacific Links in Observed Multidecadal SST Variability: Is the Atlantic Multidecadal Oscillation's Phase Reversal Orchestrated by the Pacific Decadal Oscillation?
}

\author{
Sumant NigAm, ${ }^{\mathrm{a}, \mathrm{b}}$ Agniv SENGUPTA, ${ }^{\mathrm{c}}$ AND AlFRedo RuIZ-BARRAdAS \\ Department of Atmospheric and Oceanic Science, University of Maryland, College Park, College Park, Maryland
}

(Manuscript received 5 December 2019, in final form 16 March 2020)

\begin{abstract}
The Atlantic and Pacific basin are found linked in the context of multidecadal SST variability from analyses of 118 years of observational data. Recurrent spatiotemporal variability, including multidecadal modes, was identified using the extended-EOF technique in a longitudinally global domain, allowing unfettered expression of interbasin interactions. The physicality of the obtained decadal modes was assessed using fishery records and analog counts.

A three-mode structure with bi-directional interbasin links frames the new perspective on the cycling of multidecadal SST variability. The three modes are the Atlantic multidecadal oscillation (AMO), low-frequency North Atlantic Oscillation (LF-NAO), and North Pacific decadal variability [PDV-NP; resembling negative (-ve) PDO]. The two previously documented links AMO $\rightarrow$ PDV-NP (with 12.5-yr lead) and LF$\mathrm{NAO} \rightarrow$ AMO (with 16-yr lead) are corroborated, while a third one, PDV-NP $\rightarrow(-$ LF-NAO) with $\sim 6.5-\mathrm{yr}$ lead, is uncovered. The interaction triad closes the loop on the cycling of multidecadal SST variability, generating AMO's phase reversal in $\sim 35$ years, consistent with its widely noted $\sim 70$-yr time scale. The two previously noted links - one intrabasin and one interbasin-were unsuccessful in this regard.

Other findings include the deeper subsurface extensions of Atlantic multidecadal SST variability, and the hitherto unrecognized similarity of Pan-Pacific decadal variability and North Pacific Gyre Oscillation. Instrumental records, albeit short in the context of multidecadal variability, must continue to be mined for insights into the functioning of the climate system as its model representations while improving, remain inadequate.
\end{abstract}

\section{Introduction}

Sea surface temperature (SST) exerts a significant, and often predictable, influence on Earth's climate. Interannual SST variations related to El Niño-Southern Oscillation (ENSO), for instance, impact the Indian summer monsoon to the west (Rasmusson and Carpenter 1983 ) and the North American hydroclimate to the east (e.g., Ropelewski and Halpert 1987; Joseph and Nigam 2006). Decadal SST variations have been implicated in

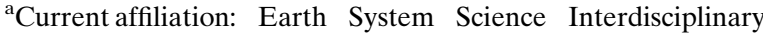
Center (ESSIC), University of Maryland, College Park, College Park, Maryland.

${ }^{\mathrm{b}}$ Additional affiliation: Fulbright-Nehru Fellow, Indian Institute of Technology (IIT), Mandi, Himachal Pradesh, India.

${ }^{\mathrm{c}}$ Current affiliation: Jet Propulsion Laboratory, California Institute of Technology, Pasadena, California.
}

Corresponding author: Sumant Nigam, nigam@umd.edu notable hydroclimate episodes: The 1930s "Dust Bowl" drought over the Great Plains of North America has been linked to decadal SST variability in the Pacific (e.g., Ting and Wang 1997; Nigam et al. 1999; McCabe et al. 2004; Seager et al. 2005; Nigam et al. 2011) and Atlantic (e.g., Namias 1966; McCabe et al. 2004; McCabe and Palecki 2006; Ruiz-Barradas and Nigam 2005; Nigam et al. 2011) basins. The 1950s-80s "drying" of the Sahel has also been attributed to multidecadal SST variations (Folland et al. 1986; Giannini et al. 2003; Zhang and Delworth 2006; Nigam and Ruiz-Barradas 2016; Thomas and Nigam 2018).

Regional hydroclimate predictions can as such benefit from the improved characterization of the nascent and mature phases (i.e., evolution) of the recurrent, pertinent interannual and decadal SST variations-a key goal of this analysis. Coherent large-scale SST anomalies on interannual-to-multidecadal time scales result not only from ocean wave dynamics (as in, but not limited to, tropical basins) and the overlying atmospheric 
circulation and related surface energy fluxes (as in extratropical basins; Frankignoul and Hasselmann 1977; de Coetlogon and Farnkignoul 2003; Deser et al. 2003, 2010), but also from heat transports by ocean currents and coastal and equatorial upwelling. Large-scale SST anomalies in one basin can moreover impact SSTs in the other basins through the atmospheric bridge (e.g., Alexander et al. 2002; Liu and Alexander 2007), thwarting efforts to unravel regional versus remote contributions in SST evolution.

Evolution-centric analysis of recurrent SST variability has been undertaken in the Pacific (Guan and Nigam 2008, hereafter GN2008) and Atlantic (Guan and Nigam 2009, hereafter GN2009) basins, but seldom in both basins together (i.e., without a priori specification of basin preference). While conducting such an analysis is the preeminent goal of this study, interbasin links have been studied before albeit in a piecemeal manner.

The impact of ENSO on the tropical Atlantic (e.g., Hameed et al. 1993; Enfield and Mayer 1997; Chung et al. 2002; Alexander et al. 2002) or of the Atlantic Niño on ENSO (e.g., Ham et al. 2013), or of these both on regional climate (Wang 2006), has been studied; see Liu and Alexander (2007) for an overview. The impact of tropical Indo-Pacific SSTs on North Atlantic SST variability has also been assessed (Hoerling et al. 2001; Bader and Latif 2003). On longer time scales, the recent warming of the tropical Atlantic was linked with intensification of the Walker circulation and related eastern Pacific cooling (Chikamoto et al. 2012; McGregor et al. 2014; Li et al. 2015).

The Atlantic and Pacific basins are linked on multidecadal time scales as well. In seminal investigations, d'Orgeville and Peltier (2007) from observational analysis and Zhang and Delworth (2007) from observational and modeling analyses uncovered links between these basins, finding the Atlantic multidecadal oscillation (AMO) leading the Pacific decadal oscillation (PDO) by 12-13 years; Wu et al.'s (2011) and Marini and Frankignoul's (2014) observational analyses support this AMO lead over the PDO. Chafik et al. (2016) indicate a prominent role of the subpolar North Atlantic (SPNA) in fostering Atlantic-Pacific links through the propagation of heat anomalies from the Gulf Stream region to the SPNA. The Atlantic pacemaker experiments of Sun et al. (2017) show the AMO to be teleconnected with decadal variability in the western tropical Pacific.

The modes of decadal-multidecadal SST variability in the Atlantic and Pacific basins, and especially the interbasin interactions in their evolution, are the principal targets of this analysis. The mature phase of these modes is reasonably well known but their characteristic evolution and development mechanisms remain uncertain.
The origin of multidecadal variability in the North Atlantic, for example, is being actively investigated. The role of oceanic processes, especially heat transports through modulation of Atlantic meridional overturning circulation (e.g., Delworth et al. 1993; Knight et al. 2005; Latif and Keenlyside 2011), is being assessed relative to atmospheric forcing through surface fluxes, both aerosolinfluenced radiative fluxes (e.g., Booth et al. 2012) and stochastic heat flux variations (Clement et al. 2015). Zhang et al. (2013, 2016), Zhang (2017), Delworth et al. (2017), O'Reilly et al. (2016), Drews and Greatbatch (2016), and others have stressed the importance of ocean circulation in the generation of multidecadal variability. Decadal fluctuations in the subpolar North Atlantic salinity and heat content were recently shown to result from a process sequence involving surface flux forcing, coastal upwelling, Ekman transports, ocean circulation, and bathymetric influences (Nigam et al. 2018).

The SST variability is analyzed in this study using the extended empirical orthogonal function extended-EOF technique, which extracts variability modes based on both spatial and temporal recurrence, without imposing any periodicity constraints and data preprocessing conditions. As such, it is able to depict the spatiotemporal evolution of recurrent variability-unlike canonical EOF analysis, which identifies the mature-phase spatial structure (i.e., pattern) but not the space-time structure (i.e., mode) of variability. ${ }^{1}$ The technique yields characterization of secular warming (through a nonstationary secular trend) and multidecadal variability, contextually (i.e., from the same single analysis), as opposed to the more common residual estimation of either component; a contextual separation is deemed essential for detection and attribution of climate change. Unlike GN2008 and GN2009, this analysis pursues contextual characterization of multidecadal SST variability also in the basin realm, that is, without prejudicing the analysis with an a priori basin preference, as was the case earlier; GN2008 analyzed Pacific basin variability while GN2009 analyzed the Pacific-unrelated variability in the Atlantic basin. In addition to allowing full expression of interbasin links via a longitudinally global analysis domain

\footnotetext{
${ }^{1}$ Prior analyses of global SST variability used the EOF technique after preprocessing the SST record through time series normalization (Kawamura 1994), low-pass filtering (Enfield and MestasNuñez 1999), mode rotation (Mestas-Nuñez and Enfield 1999), and separation of seasons (Yasunaka and Hanawa 2005); no preprocessing was used in Messié and Chavez (2011). Chen et al. (2017) used pairwise rotation of EOFs to eliminate mode mixing. The present analysis uses the extended-EOF technique (Weare and Nasstrom 1982), followed by varimax rotation (Kaiser 1958); see GN2008 and GN2009 for elaboration on the relative advantages of this strategy.
} 
$\left(20^{\circ} \mathrm{S}-80^{\circ} \mathrm{N}\right)$, this analysis is based on 15 more years of recent data vis-à-vis GN2008; the 1900-2018 SST record is its target.

The physicality of multidecadal modes is assessed using Pacific and Atlantic fish recruitment data as well as observational analog counts; Pacific recruitment records were augmented and the Atlantic ones sourced for this assessment. Sensitivity tests, including varying the sampling window width and the number of rotated modes, are performed to assess the robustness of the final analysis.

Datasets and analysis method are briefly described in section 2. Principal components and modal evolution from the primary analysis are discussed in sections 3 and 4 where the focus is on decadal to multidecadal variability; modal links with ocean subsurface temperature and salinity are documented in section 4. The simultaneously extracted interannual variability modes (e.g., ENSO growth and ENSO decay) are displayed in the appendix, for completeness. Intra- and interbasin links between multidecadal modes, revealed by lead-lag analysis and supported by spatiotemporal evolutions, are presented in section 5 with a brief commentary on related atmospheric circulation, which is a key linking agent. The sensitivity of the primary analysis and the physicality of extracted modes are discussed in section 6 , with concluding remarks following in section 7 .

\section{Datasets and analysis method}

\section{a. Sea surface temperature}

The U.K. Met Office's Hadley Centre Sea Ice and Sea Surface Temperature data (HadISST 1.1; Rayner et al. 2003), available monthly from 1900 to 2018 on a $1^{\circ}$ grid, are analyzed. For computational efficiency, monthly SSTs are regridded onto a $5^{\circ} \times 2.5^{\circ}$ longitude-latitude grid. Seasonal SSTs are computed using Northern Hemisphere season definitions (e.g., winter is the DecemberFebruary average). Seasonal SST anomalies are constructed by removing the long-term climatology of each season. The same procedure is used for other variables in the study.

\section{b. Mean sea level pressure}

The Met Office's Hadley mean sea level pressure data (HadSLP2; Allan and Ansell 2006) are used to infer the surface atmospheric circulation associated with SST evolution. The dataset, a combination of land and marine pressure observations, is available at monthly resolution on a $5^{\circ}$ global grid from 1850 to the present.

\section{c. Subsurface temperature and salinity}

The Met Office's Hadley Centre-produced, qualitycontrolled EN.4.2.1 dataset (Good et al. 2013), which was bias-corrected using the climatological World Ocean Atlas 2009 (Levitus et al. 2009), is used for the analysis of ocean subsurface temperature (including heat content) and salinity. The data are available at monthly resolution on a $1^{\circ}$ grid from 1900 to the present.

\section{d. Analysis method}

Seasonal SST anomalies in a longitudinally global domain $\left(20^{\circ} \mathrm{S}-80^{\circ} \mathrm{N}, 0^{\circ}-360^{\circ}\right)$ are analyzed from winter 1900 to winter 2017/18 using the extended-EOF technique (Weare and Nasstrom 1982). A five-season-long sampling window is used in the primary analysis, followed by varimax rotation (e.g., Richman 1986) of the leading principal components (PCs). The analysis closely follows GN2008 in its implementation of the extended-EOF technique, sampling window, and PC rotation. Eleven PCs were rotated in order to accord this global analysis the same degrees of freedom (i.e., variability modes) as that available in total in the related individual basin analyses (GN2008; GN2009); the choice of 11 was also guided by physicality assessments of the modes, through analog counts and PC correlation with fishery records (cf. section 6). Because of the focus on both spatial and temporal recurrence, the analysis yields recurrent modes (and not just patterns) of variability; specifically, a five-season-long spatiotemporal pattern (loading vector, or extended EOF) and its related time series (principal component) are obtained for each mode.

The SST principal components are smoothed, when noted, using the LOESS filter (Cleveland and Loader 1996) with a $10 \%$ span window (LOESS-10\%; or with window span equaling $10 \%$ of the 118 -yr record, or $\sim 12$ years). The smoothing suppresses seasonal-to-interannual variations, thereby highlighting decadal-to-multidecadal variability.

The evolution of SST (and other related variables) can be obtained from the linear lead-lag regressions of their seasonal anomalies on the principal components, smoothed or unsmoothed. Note that linear regressions of SST on any $\mathrm{PC}$ in the \pm 2 -season window completely recover the related SST loading vector that was initially obtained. Standard statistical tools such as autocorrelation and cross-correlation are used to estimate modal time scale and intermodal links, respectively.

\section{e. Physicality of multidecadal variability modes}

Hare and Mantua's (2000) pioneering use of marine ecosystem data in evaluating the physicality of Pacific decadal oscillation (obtained from statistical analysis of SSTs) opened a new avenue in physicality assessment —one pursued by GN2008, who also used observational analog counts. North Pacific and the Bering Sea recruitment is 
assembled from Hare and Mantua (2000; data period 1965-97), the International Pacific Halibut Commission (IPHC) regulatory areas $3 \mathrm{~B}$ and $4 \mathrm{~A}^{2}$ catchment (data period 1991-2014), and from two IPHC models (Stewart and Martell 2014) for a more extended period (19252010). For the Atlantic basin, stock assessment records for mackerel (NEFSC 1996, 2006, 2018), Gulf of Maine cod (Palmer 2014), menhaden (SEDAR 2015), and the Norwegian herring (Toresen and Østvedt 2000; ICES 2011) were used in physicality assessments of the Atlantic basin modes.

As the observational realization of a statistically extracted mode is the ultimate proof of its physicality, the observed SST anomalies were objectively scanned to detect instances when they closely resembled any one of the leading modes; an observational analog was recorded when this occurred and the total analog count was an evaluative metric for the physicality of modes (see GN2008 for how resemblance was objectively assessed).

An array of sensitivity tests and mode-physicality assessments lead to the choice of the five-season-wide sampling window and the rotation of 11 leading modes in the $20^{\circ} \mathrm{S}-80^{\circ} \mathrm{N}$ basin for the primary analysis.

\section{Spatiotemporal analysis of SST variability: Pacific decadal variability}

The section begins with the display of principal components of all the 11 variability modes (Fig. 1). The originally extracted PCs and their smoothed versions are shown, along with and in the order of explained variance. The decadal variability modes in the Pacific are presented in this section. ${ }^{3}$ Pacific decadal variability (PDV) is represented by two modes in this analysis, as in GN2008: the Pan-Pacific (4th leading) and North Pacific (7th leading) modes; the more familiar North Pacific mode is discussed first. Modal evolution over a 5-yr period is shown in Fig. 2.

\section{a. North Pacific mode (PDV-NP)}

The mature phase of the North Pacific mode (Deser and Blackmon 1995; Nigam et al. 1999; Barlow et al. 2001; GN2008) consists of a zonal band of warm SST anomalies $(\sim 0.3 \mathrm{~K})$ extending from the coast of Japan into the central-eastern midlatitude Pacific, and negligible anomalies elsewhere (cf. Fig. 2, right column, $t$ ).

\footnotetext{
${ }^{2}$ The IPHC regulatory areas are described in their Tech. Rep. 49 (Kong et al. 2004).

${ }^{3}$ The interannual ones (including ENSO) and the secular trend mode are shown in the appendix.
}

The 1-yr precursor phase, however, is more populated, with cold anomalies additionally present in the centraleastern equatorial Pacific, i.e., in the cold-tongue domain (e.g., marked in Nigam and Chao 1996). The evolution of the PDV-NP mode is very similar to that displayed in GN2008 (Fig. 12) and the depicted 5-yr evolution is just a snapshot given the mode's multidecadal time scale (estimated later in this section). PDV-NP has more extensive links to the tropics than evident from the displayed regressions: Its links to the southern Indian Ocean and western Pacific become apparent in SST correlations (Fig. 3a), which, unlike regressions, are not adversely impacted by the small SST variability amplitude in this region. The PDV's link with the tropical Indian basin has been noted earlier (Deser et al. 2004; GN2008, their Fig. 12).

The PDV-NP mode closely resembles Mantua et al.'s (1997) Pacific decadal oscillation, as noted in GN2008. The PDV-NP PC and PDO index are maximally correlated when PDV-NP lags PDO (Fig. 3b): at -0.56 at 2 season lag (unsmoothed) and -0.79 at 1-yr lag (smoothed). The negative correlations indicate that the PDV-NP's positive phase (displayed in Fig. 2) corresponds to the PDO's negative phase. Both capture the 1976/77 shift to a colder Pacific surface state. The PDVNP and PDO exhibit subtle differences, the above similarities notwithstanding, notably from the extension of PDO's coastal footprints into the Gulf of Alaska (Fig. 2a in Mantua et al. 1997; Fig. 3 here) - a feature not present in PDV-NP's evolution (Figs. 2 and 3).

\section{b. Pan-Pacific mode (PDV-PP)}

The Pan-Pacific (PP) mode's mature phase (Fig. 2; left column, $t$ ) consists of warm SSTs along the North American coast extending from the Aleutians to Baja California and then southwestward into the central tropical Pacific; the horseshoe structure surrounds weaker cold SSTs in the central midlatitude basin. The mode was first documented by GN2008 (see their Fig. 11, left column). Its PC (Fig. 1) indicates a multidecadal transition in the 1930 s to a warmer coastal state which ended in the 1990s. Its cold phase since the early 2000s, notably, around 2010, and the following transition to the warm phase in $\sim 2013$ is relevant in the context of the warm "blob" of water that persisted in the northeastern Pacific for a few years since 2013 (Bond et al. 2015). In recent decades, since at least 2000, the PDV-PP mode has been more energetic than the PDV-NP one.

The PDV-PP SSTs resemble the horseshoe-shaped, coastally focused SSTs associated with North Pacific Gyre Oscillation (NPGO; Di Lorenzo et al. 2008, Fig. 4b), the second leading EOF of modeled sea surface height 


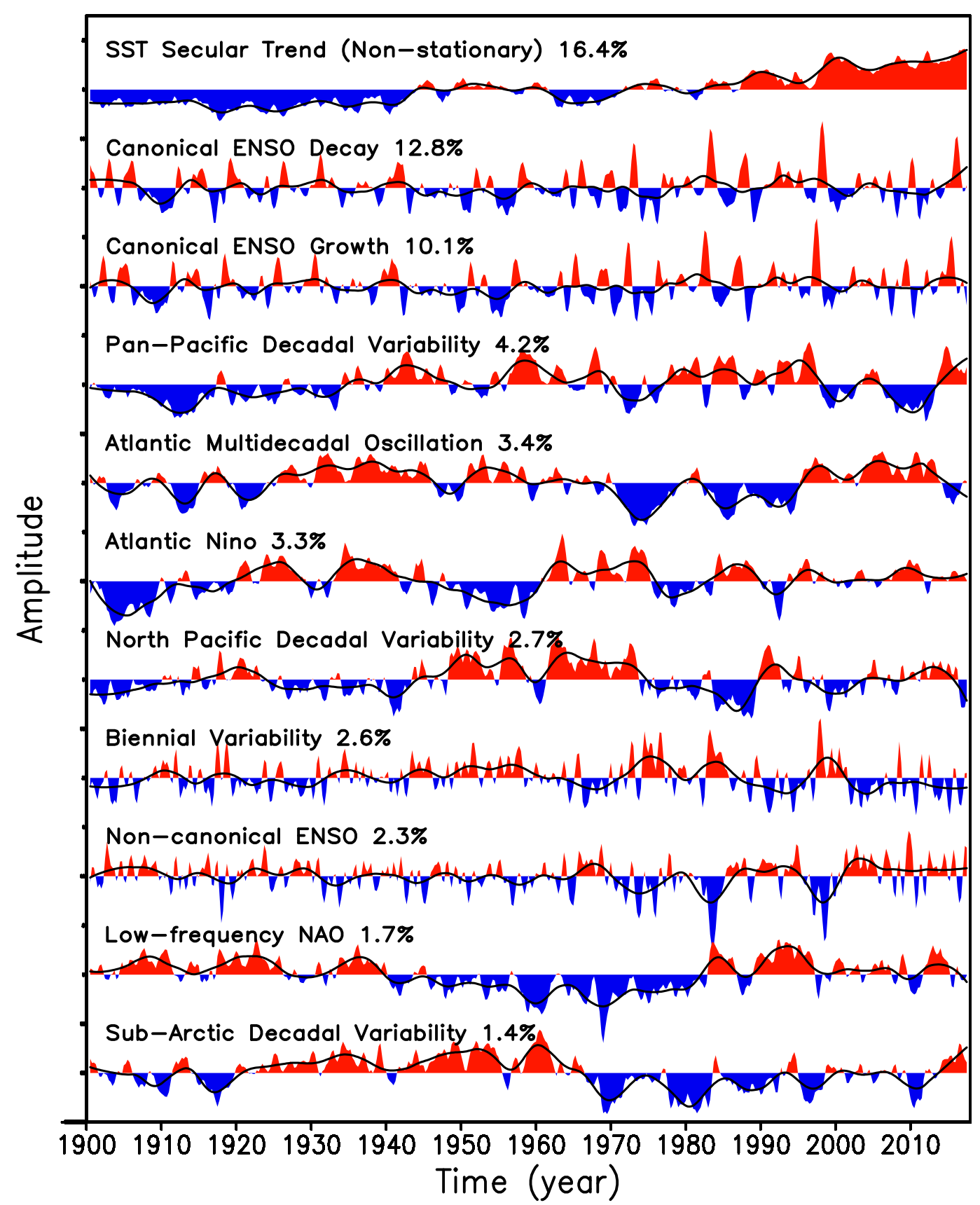

FIG. 1. Leading principal components (PCs) of global SST variability obtained from an extended-EOF analysis of Hadley Centre SSTs; the PCs extend from 1900 (summer) to 2017 (summer). Tick marks on the vertical axis are drawn every three standard deviations. The original, seasonally resolved PCs are shaded while their smoothed versions (from LOESS-10\% smoothing) are shown using solid black lines. The percentage of SST variance explained by each mode of spatiotemporal variability is indicated next to its name.

variations in the extratropical basin. Despite this resemblance, the connection between the two has, surprisingly, remained uninvestigated. The similarity is stronger in the SST regressions of the common period (1950-2017), as shown in Fig. 4 (top panels). The extensive correspondence between the regressions of upper-ocean $(5-657 \mathrm{~m})$ heat content and salinity on the Pan-Pacific PC and the NPGO index (Di Lorenzo 2019 ) in Fig. 4 (middle panels) underpins the close link between them. Temporally, the Pan-Pacific PC and the 

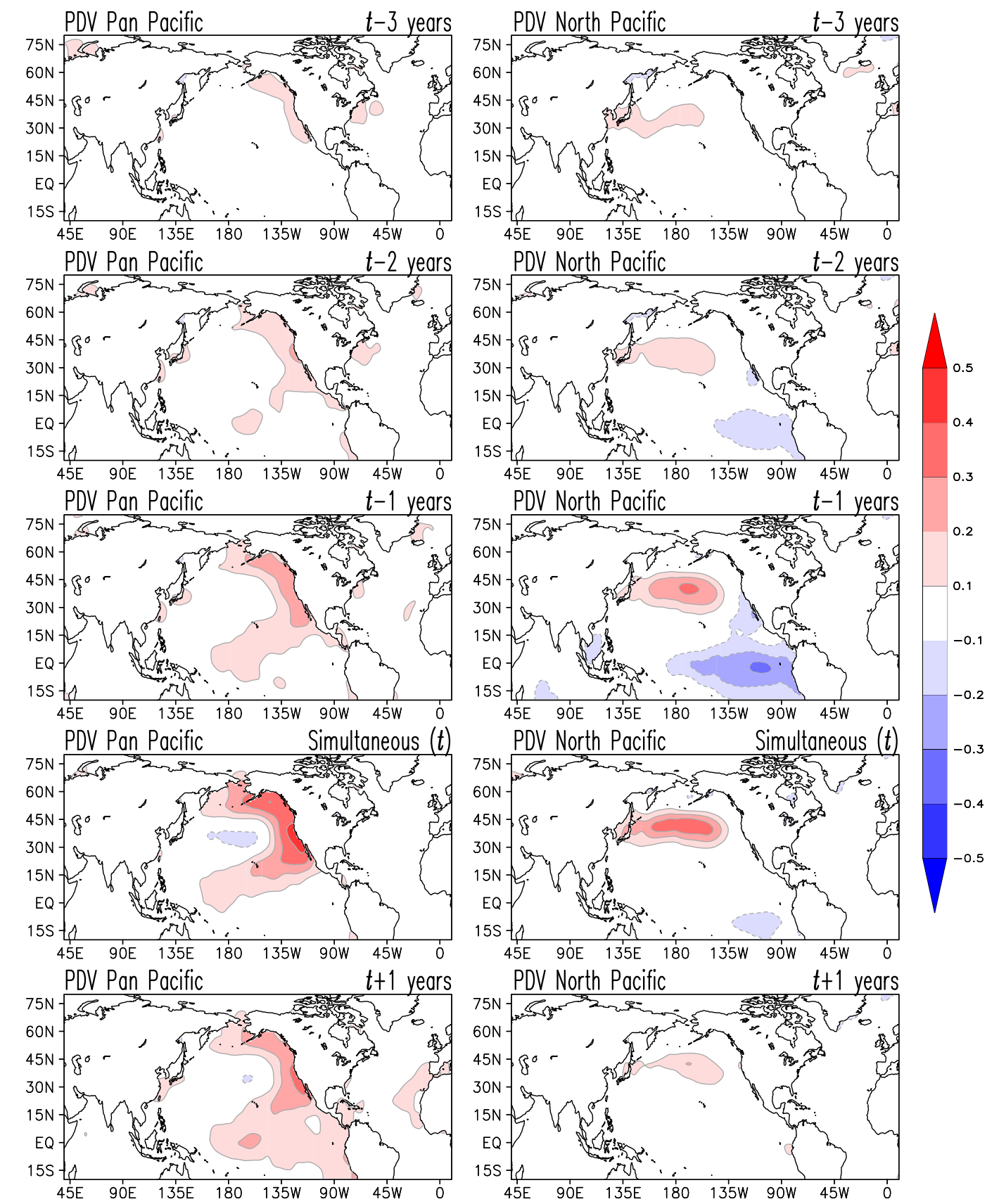

FIG. 2. Spatiotemporal evolution of Pacific decadal SST variability: The (left) Pan-Pacific (PDV-PP) and (right) North Pacific (PDV-NP) modes are displayed over a 5-yr span at yearly intervals, with time running downward in both columns. Lead-lag regressions of the seasonal SST anomalies on the PDV-PP and PDV-NP PCs over 19002017 are displayed, with label $t$ denoting simultaneous regressions. Red (blue) shading denotes positive (negative) SST anomalies, and the zero contour is suppressed. The contour interval and shading threshold is $0.1 \mathrm{~K}$. The fields are displayed after 12 applications of the function "smth9" in GrADS.

NPGO index links are less impressive: The two are found maximally correlated at a two-season lag, with PDV-PP leading; the correlation is -0.56 for the unsmoothed and -0.69 for the smoothed records (Fig. 4 , bottom panel).
The PDO and NPGO indices are concurrently correlated at -0.18 and their smoothed versions at -0.30 , indicating some overlap. The PDV-NP and PDV-PP principal components are however uncorrelated as mandated by the extended-EOF analysis, including PC 

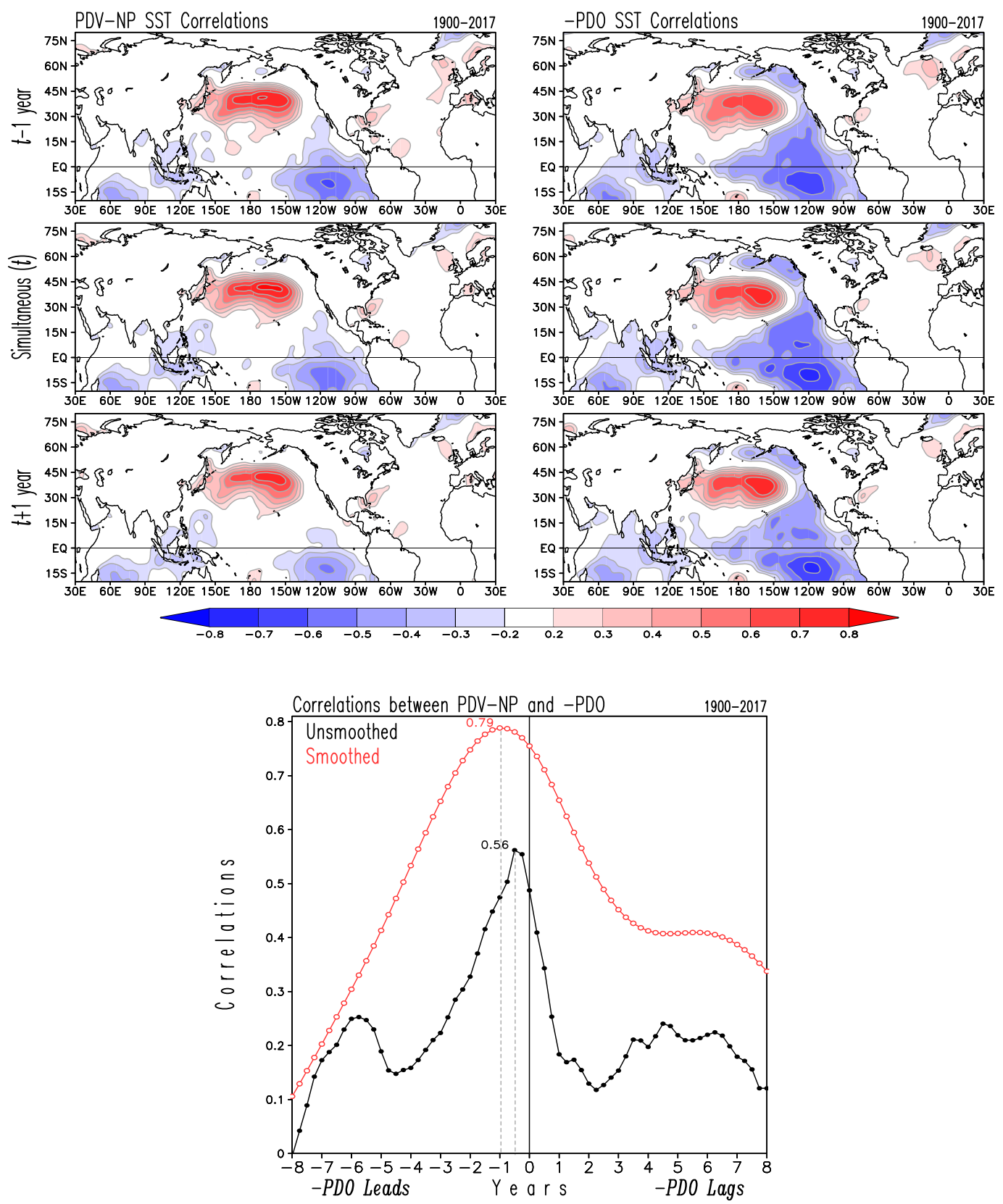

FIG. 3. The PDV-North Pacific SST variability mode (PDV-NP) and Pacific decadal oscillation (PDO). (top) Leadlag SST correlations on (left) the PDV-NP principal component and (right) the negative PDO index over 1900-2017; the PC, PDO index, and the SSTs were all temporally smoothed (LOESS-10\%) before computation. Red (blue) shading denotes $+(-v e)$ values starting at \pm 0.2 . Correlations were spatially smoothed with GrADS function smth9, applied 12 times. (bottom) Lead-lag correlations of the PDV-NP PC and the negative PDO index over 1900-2017 are displayed, both before (black curve) and after LOESS- $10 \%$ smoothing (red curve). The two are maximally correlated at 0.56 (0.79) at a 2-season (1 yr) lead of the unsmoothed (smoothed) negative PDO index. Note that correlations larger than $0.19(0.33)$ are statistically significant at the $95 \%$ confidence level for the unsmoothed (smoothed) time series, as assessed by a two-tailed Student's $t$ test after factoring for serial correlation [following Metz (1991)].

rotation. Smoothing destroys the orthonormality of PCs but, evidently, not by much; the smoothed PCs are concurrently correlated at -0.01 . The PDV-NP and PDV-PP modal structures thus constitute an optimal basis for resolving multidecadal SST variations in the Pacific basin; the PC correlations with Pacific marine ecosystem data, discussed in section 6 , support this assessment. 

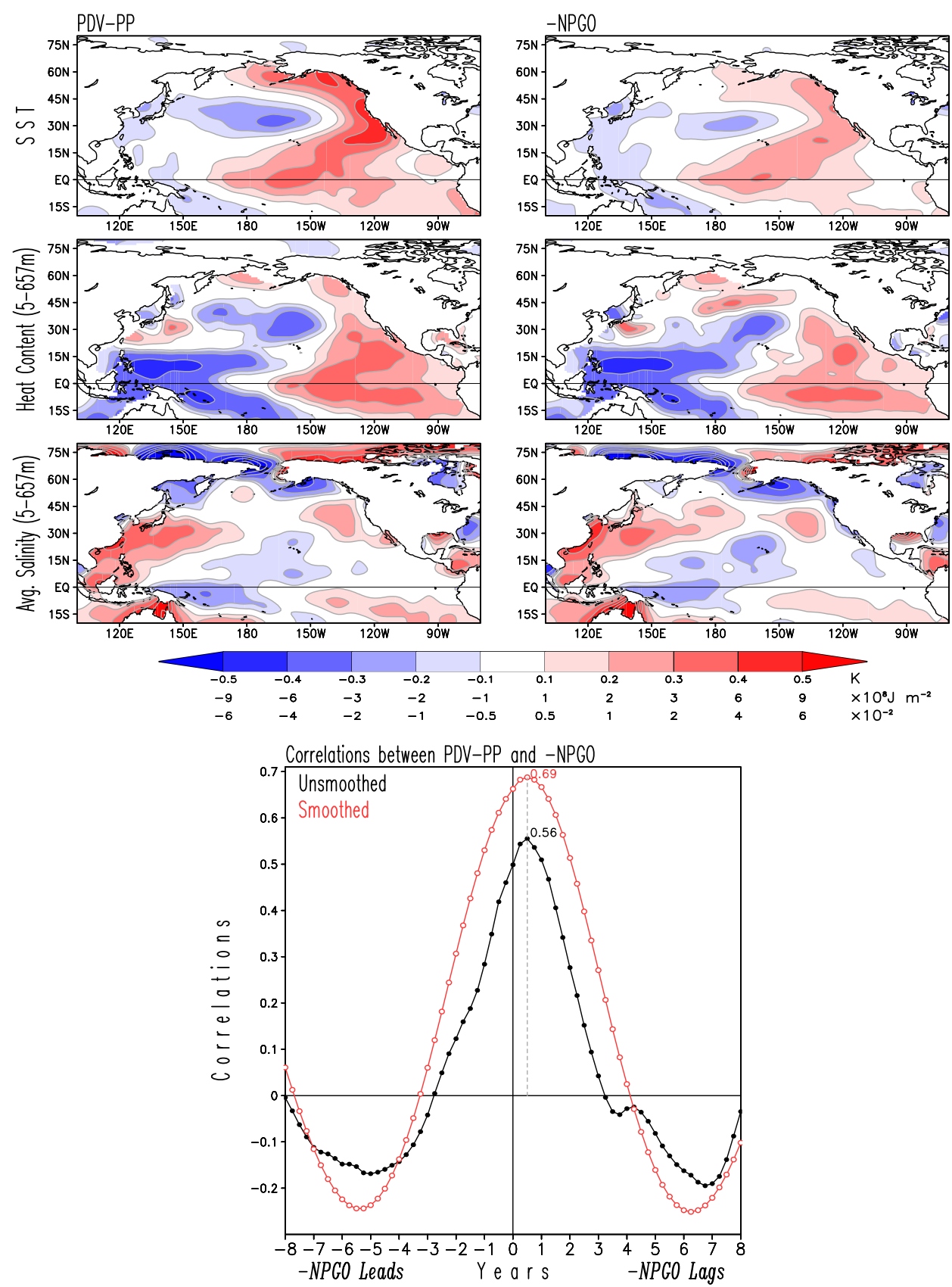

FIG. 4. The PDV-Pan-Pacific SST variability mode (PDV-PP) and North Pacific Gyre Oscillation (NPGO): Simultaneous upper-ocean regressions on (left) the smoothed PDV-PP principal component and (right) the negative NPGO index in the common 1950-2017 period are shown in the upper panels; time series were smoothed to retain similar decadal-to-multidecadal variabilities from the use of $10 \%$ LOESS filter on the 118-yr-long PC and a $17 \%$ filter on the 69 -yr-long index. (top) SST (K), (middle) upper-ocean $(5-657 \mathrm{~m})$ heat content $\left(10^{8} \mathrm{~J} \mathrm{~m}^{-2}\right)$, and (bottom) vertically averaged $(5-657 \mathrm{~m})$ salinity $\left(10^{-2}\right)$ regressions are displayed after spatial smoothing with GrADS function smth9, applied 12 times and plotted using the shading and threshold specified in the color bar; the subsurface fields are from EN.4.2.1 data. Lead-lag correlations of the PDV-PP PC and the negative NPGO index over 1950-2017 are displayed in the lower panel, both before (black curve) and after smoothing (red curve). The two are maximally correlated at $0.56(0.69)$ at two-season lead of the PDV-PP PC. Note that correlations larger than $0.27(0.38)$ are statistically significant at the $95 \%$ confidence level for the unsmoothed (smoothed) time series, as assessed by a two-tailed Student's $t$ test after factoring for serial correlation [following Metz (1991)]. 

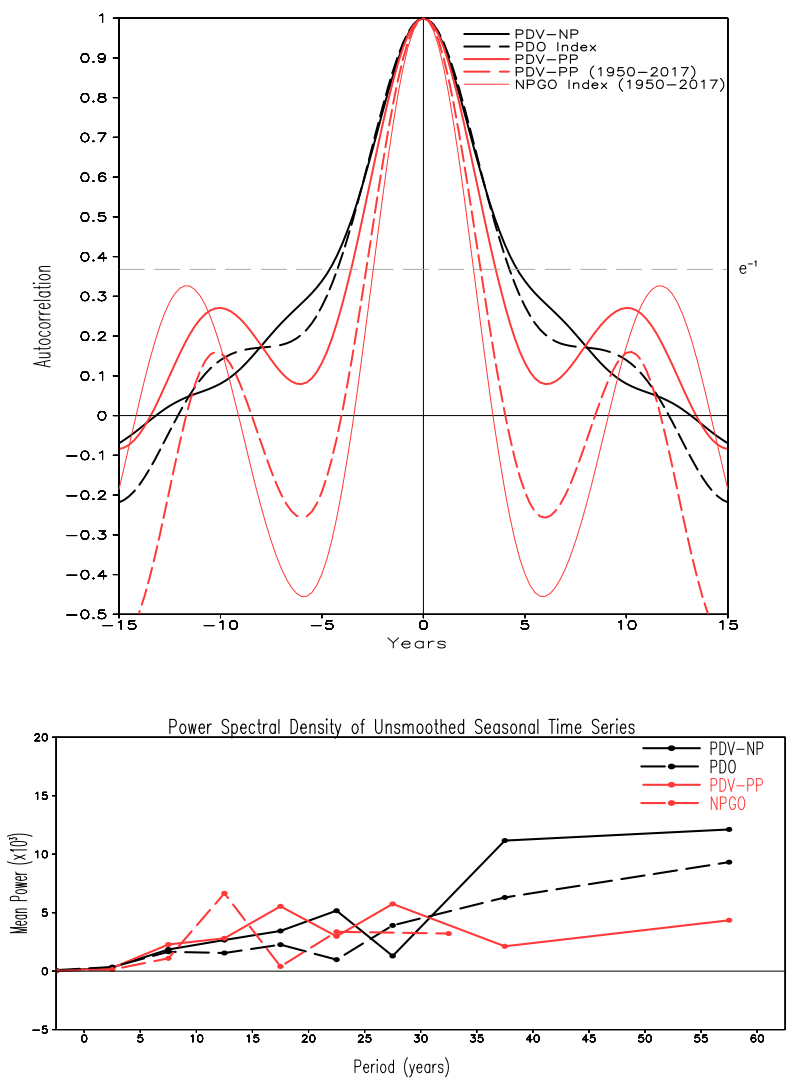

FIG. 5. Pacific decadal variability time scales: (top) Autocorrelations of the PDV-North Pacific (solid black) and PDV-Pan-Pacific (solid red) principal components are compared with that of the Pacific decadal oscillation (PDO; dashed black) and North Pacific Gyre Oscillation (NPGO; thin red). PDV-NP and PDO autocorrelations were obtained from their LOESS- $10 \%$ smoothed versions over 1900-2017. Autocorrelation of the similarly smoothed PDV-PP PC are in solid red for the full period (1900-2017) and dashed red for the latter half (19502017). To facilitate comparison, the NPGO index was smoothed with a LOESS-17\% filter over 1950-2017, so as to retain time scales similar to those in PDV-PP. Autocorrelations of the smoothed NPGO index are in thin red. (bottom) Power spectra of the unsmoothed Pacific PCs/indices. The mean of the spectral peaks identified in each 5-yr bin $(1-5,6-10,11-15-, \ldots, 56-60$ years) are plotted for the PDV-NP (solid black), PDO index (dashed black), PDV-PP (solid red), and the NPGO index (dashed red), with the $x$ axis showing the period (in years). See legend for more details. The NPGO spectra are curtailed in view of the shorter record length.

\section{c. Variability time scale}

Autocorrelation structure of the LOESS-10\% smoothed PDV principal components and the equivalently smoothed PDO and NPGO indices are examined to estimate variability time scales (Fig. 5, top). For periodic variations, the oscillation period is twice the temporal distance between the zero-crossings of the autocorrelation. Autocorrelations of PDV-NP and PDO are similar, with no secondary peaks and nearly coincident zero-crossings at $\sim 13$ years, yielding a $50-55-\mathrm{yr}$ variability time scale that is broadly consistent with its earlier estimate (60 years; d'Orgeville and Peltier 2007). Autocorrelation of the PDV-PP, in contrast, exhibits "wings" (i.e., a nonmonotonic decrease with increasing lead and lag, confounding time scale estimation); consideration of the zero-crossings alone yields a $\sim 50$-yr time scale for the PDV-PP mode. Autocorrelation is also computed for the NPGO and compared with that of PDV-PP in the common period (1950-2017). The comparison reveals reasonably similar zero-crossings, the first of which occurs much earlier than in PDV-PP's full-period autocorrelation (thick red line), indicating an estimation bias toward shorter time scales in the shorterperiod analysis.

Quantitative estimation of variability time scales is accorded by the power spectra of the unsmoothed time series (Fig. 5, bottom). PDV-NP and PDO exhibit similar spectra (with a primary peak at 55-60 years and secondary peaks at 35-40 and 20-30 years) representing multidecadal periods, with PDV-NP having more power at nearly all periods; the PDO's 60- and 20-yr time scales have been noted before (d'Orgeville and Peltier 2007). The PDV-PP and NPGO, however, exhibit differences: NPGO's primary peak is at $10-15$ years while PDV-PP's is at 25-30 (and also 15-20 and 55-60) years, with the PDV-PP having more power at longer periods.

\section{Spatiotemporal analysis of SST variability: Atlantic multidecadal variability}

Multidecadal SST variability in the Atlantic basin consists of at least two modes of variability: the Atlantic multidecadal oscillation (AMO; Enfield et al. 2001; GN2009; Kavvada et al. 2013; Ruiz-Barradas et al. 2013; Nigam et al. 2018), with warm footprints in the subpolarto-subtropical basins in its positive phase and an approximate 7-decade time scale (cf. Fig. 1), and low-frequency North Atlantic Oscillation (LF-NAO), a decadal-tomultidecadal variability mode known variously for over half a century (Bjerknes 1964; Rogers 1984; Hurrell 1995; Joyce et al. 2000; Marshall et al. 2001; Nigam 2003; Czaja et al. 2003; Hurrell et al. 2003; Zhang and Vallis 2006; Álvarez-García et al. 2008; GN2009; Sun et al. 2015; Gastineau and Frankignoul 2015; Nigam et al. 2018; and others). LF-NAO is a tripolar SST pattern, with warm anomalies off Newfoundland and southwestto-northeast sloping cold anomalies in the subtropical and northeastern Atlantic basin, in its positive phase. The AMO (5th leading) and LF-NAO (10th leading) mode evolution are shown in Fig. 6. 


\section{a. Atlantic multidecadal oscillation}

A 10-yr evolution of AMO SSTs (Fig. 6, left) shows notable subpolar anomalies in the Labrador and Irminger Seas in the premature phase ( $t-4$ years). Two years later ( $t-2$ years), warm SSTs are found along the western flank of the subpolar gyre, continuing southward along the Grand Banks. The southeastward extension of warm SSTs at this time and their rapid development toward and along the African coast in subsequent years suggest entrainment of the warm subpolar anomalies into the subtropical gyre, and their anticyclonic development hence. In the mature phase $(t)$ of the AMO, the entire North Atlantic, except for the Sargasso Sea, is warm; SST anomalies are $\sim 0.4^{\circ} \mathrm{C}$ in the subpolar basin, with a weaker extension into the subtropics and the tropics that bears resemblance to the interhemispheric variability mode in the Atlantic (e.g., Ruiz-Barradas et al. 2000). The 10-yr evolution (Fig. 6, left)-which is short in the context of AMO's multidecadal time scale-indicates a subpolar origin of the AMO SSTs followed by their southeastward advance and development in the North Atlantic basin, much as described in GN2009 (Fig. 4) and Kavvada et al. 2013 (Fig. 5). In short, the AMO SST anomalies do not develop concurrently across the basin. The AMO is not apparently linked to the Pacific and Indian basin SSTs.

The AMO in this analysis closely resembles its earlier description: The NOAA-AMO index-based on the linearly detrended, area-averaged SST anomaly in the North Atlantic $\left(0^{\circ}-60^{\circ} \mathrm{N}, 75^{\circ}-5^{\circ} \mathrm{W}\right)$, following Enfield et al. (2001) and plotted in Nigam et al. (2018, their Fig. 1) - is correlated with the AMO PC at 0.69 during 1900-2017, and at 0.80 when both are LOESS-10\% smoothed. The AMO PC and the NOAA-AMO index track closely, capturing the constituent decadal pulses (Nigam et al. 2018) and the multidecadal warm-to-cold basin transition in the mid-1960s and the reverse transition in the mid-1990s; both PC and the index have increased since the mid-1970s.

Sea level pressure (SLP) regressions on the AMO PC (Fig. 6, blue contours) show lower SLP in the polar latitudes, with foci over southern Greenland and East Siberian Sea (at $t-4$ years); the former, leading to enhanced westerlies over the subpolar Atlantic. Interestingly, the underlying SSTs are warmer (i.e., opposite of what wind speed-driven intensification of surface fluxes would produce), suggesting other origins for the nascent AMO. In the mature phase $(t)$, meridional SLP gradient is reversed, leading to weakened westerlies and to underlying SST anomalies whose sign (positive), at least, is consistent with the weakening of surface fluxes. This mechanism's viability, however, depends on more than just the sign: Is a $0.4^{\circ} \mathrm{C}$ warming of the subpolar gyre consistent with an $\partial(\mathrm{SLP}) / \partial \theta$ increase of $(0.4 \mathrm{hPa}) /\left(15^{\circ}\right.$ latitude $) ?^{4}$ Notable SLP regressions in the postmature phase $(t+4$ years $)$ are found, interestingly, not in North Atlantic but in the North Pacific, indicating potential interbasin links-a topic pursued in the next section.

\section{b. Low-frequency North Atlantic Oscillation}

The low-frequency North Atlantic Oscillation (LFNAO) name stems from its notable SLP footprint over North Atlantic: a meridional dipole with a low centered over the Denmark Strait (i.e., between Greenland and Iceland) and an expansive high over the subtropical and midlatitude basin centered westward of the Azores (cf. Fig. 6, right, $t$ ), which broadly resembles the NAO positive phase (e.g., Deser et al. 2010, their Fig. 1). The two NAO index stations are marked in the LF-NAO's mature phase $(t)$ whose weak SST anomalies exhibit a triband structure, reminiscent of the NAO SST anomalies (Deser et al. 2010, their Fig. 1); note that some differences are inevitable due to differences in dominant time scale (multidecadal here vs subseasonal in Deser et al.) and seasonal stratification (all-season regressions in Fig. 6 vs winter regressions in Deser et al.). The resemblance continues in the temporal domain, with the LFNAO PC maximally correlated with Hurrell's NAO index at 0.62 at four-season lag (i.e., with LF-NAO lagging) when both PC and index are smoothed (LOESS-10\%) over the 1900-2017 period.

Unlike the AMO, the LF-NAO is associated with more impressive SLP than SST anomalies, reflecting, perhaps, an important role of atmospheric processes in

\footnotetext{
${ }^{4}$ A perusal of Fig. 1 in Deser et al. (2010) shows that a pressure difference of approximately $4.0 \mathrm{hPa}$ over $15^{\circ}$ of latitude is related to a $\sim 0.4^{\circ} \mathrm{C}$ change in subpolar gyre temperature. This pressure difference is about 10 times larger than that in AMO's mature phase, and while this discrepancy can call into question the viability of the surface flux forcing mechanism for AMO's mature-phase SSTs, one needs to take into account the larger variability time scale in AMO's case (multidecadal) versus the subseasonal scale in Deser et al.'s (2010) NAO example. For a passive mixed layer (of depth $H$ ), subject to periodic downward surface heat-flux forcing $F_{\text {srf }}$, the thermodynamic response of mixed layer temperature $T$ is $\hat{T} \approx-i \hat{F}_{\text {srf }} /\left(H C_{p} \omega\right)$, where $T(t)=\operatorname{Real}\left\{\hat{T} e^{i \omega t}\right\}$ and $F_{\text {srf }}$ is similarly represented. Although the equation governing mixed layer temperature is more complex [cf. Deser et al. 2010, their Eq. (1)], a simplified version is used here to highlight the concept of frequency modulation of forcing, i.e., the temperature response is proportional to the forcing amplitude divided by $\omega$, the variability frequency. As $\omega$ associated with multidecadal time scales is much smaller than the one associated with subseasonal NAO variability in Deser et al., a realistic multidecadal SST response is, in principle, obtainable even with an order of magnitude smaller surface-flux forcing.
} 

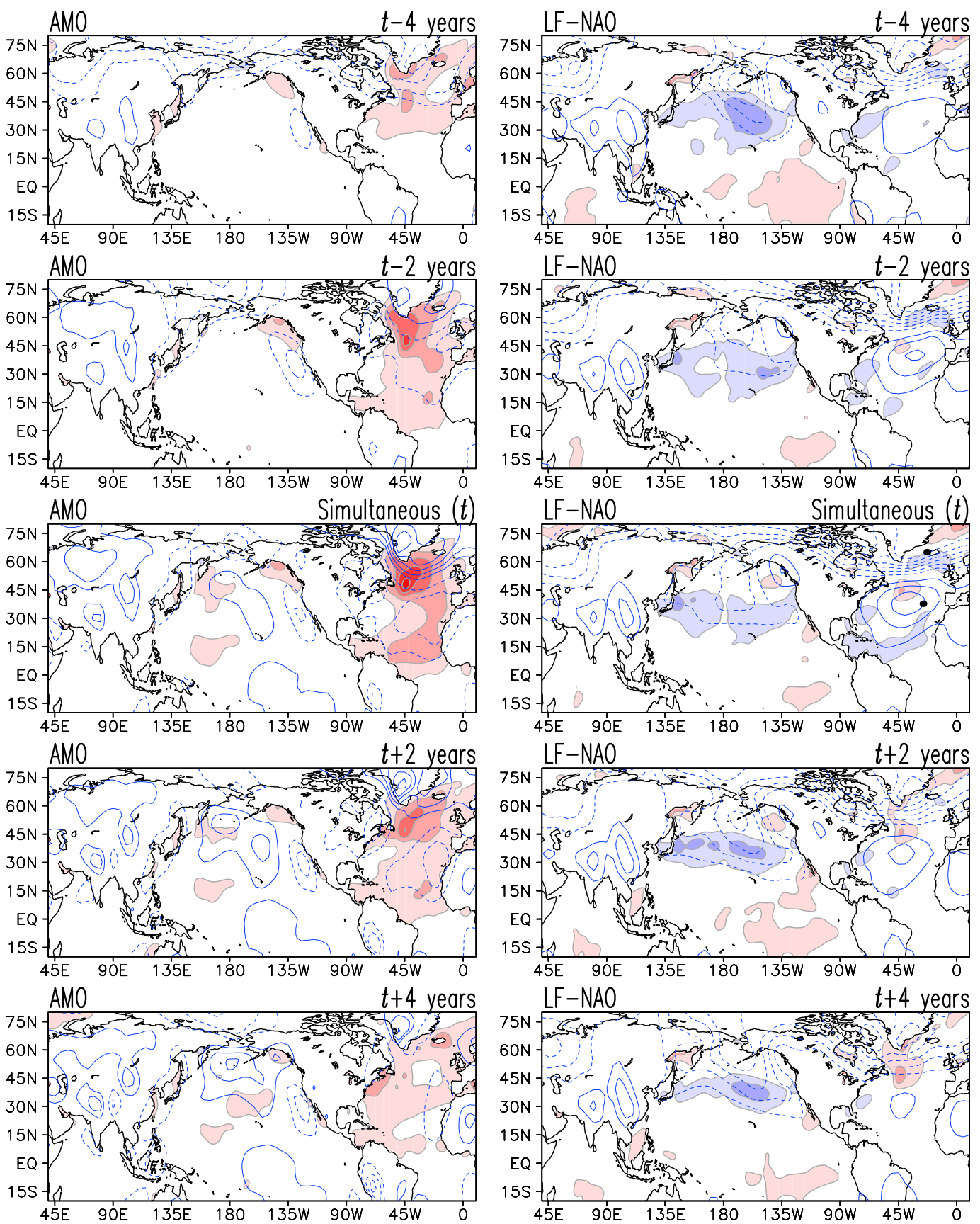

FIG. 6. Spatiotemporal evolution of Atlantic multidecadal SST variability: (left) The Atlantic multidecadal oscillation (AMO) and (right) the low-frequency North Atlantic Oscillation (LF-NAO) modes are displayed over a 10-yr span at 2-yr intervals, with time running downward in both columns. Lead-lag regressions of the seasonal SST (shaded) and sea level pressure (SLP, from HadSLP2; contoured) anomalies on the LOESS-10\% smoothed AMO and LF-NAO PCs over 1900-2017 are displayed, with label $t$ denoting simultaneous regressions. Red (blue) shading denotes positive (negative) SST anomalies, and the zero contour is suppressed. The overlaid solid (dashed) blue contours denote + ve ( - ve) SLP regressions. The contour interval and shading threshold for both regressions is 0.1 $(\mathrm{K}, \mathrm{hPa})$. The fields are displayed after smoothing from 12 applications of smth9 in GrADS. The black dots in LFNAO's mature phase mark Stykkisholmur/Reykjavik (Iceland) and Ponta Delgada (Azores), the two stations whose SLP anomalies define the synoptic monthly NAO index. 
its genesis and evolution. More interestingly, and also unlike AMO, the LF-NAO is associated with significant SST and SLP anomalies in the Pacific, notably in the midlatitude basin where a band of cold SSTs extends from the coast of Japan toward the North American coast (e.g., Fig. 6, right; $t+2$ years); the related SLP regressions indicate that these cold SSTs underlie a belt of strengthened surface westerlies. That the band of cold SSTs resembles the negative phase of the PDV-North Pacific mode (Fig. 2, right; $t$ ) is noteworthy, and suggestive of interbasin interaction, which is investigated in the next section.

\section{c. Variability time scale}

Autocorrelation of the smoothed AMO and LF-NAO PCs (Fig. 7) is similarly structured with secondary peaks but the zero-crossings indicate a longer time scale $(>80$ years) of the LF-NAO vis-à-vis the AMO ( $\sim 70$ years). The power spectrum is not shown as it was unable to identify the dominant low frequencies given the shortness of the SST record (116 years), which lead to a spectrum void between the ultimate and penultimate periods (116 and 58 years, respectively).

\section{d. Subsurface structure}

The subsurface temperature and salinity extensions of the multidecadal modes of sea surface temperature variability-AMO and the LF-NAO-are shown along transects that bisect their key SST anomalies (Fig. 8); the transects are marked on the mature-phase SST anomalies (Fig. 8, left).

The AMO transect goes through the subpolar gyre bisecting the large SST anomaly; it extends from Long Island to the southwest to Faroe Islands (between Iceland and Norway) to the northeast. The AMO temperature and salinity anomalies exhibit coherent, downsloping structure indicating the gradual sinking of warm, salty anomalies up to a depth of $\sim 1000 \mathrm{~m}$ as they head northeast along the transect. Interestingly, this transect is broadly coincident with the path of the North Atlantic Current, which must steer the AMO anomalies; these anomalies, however, do not head out of the northeastern basin as they are entrained into the subpolar gyre (Nigam et al. 2018; see their Fig. 4).

The LF-NAO transect (Fig. 8, second row) is the $\sim 45^{\circ} \mathrm{N}$ latitude line that cuts across the midbasin SST anomaly, the middle of the triband SST anomalies associated with this mode (cf. Fig. 6, right). Notable subsurface anomalies (warm and salty) are present in the western basin, confined to the near-coastal region along the Grand Banks. They represent northward excursion of the Gulf Stream, which typically follows the positive phase of the LF-NAO, with an $\sim 1$-yr

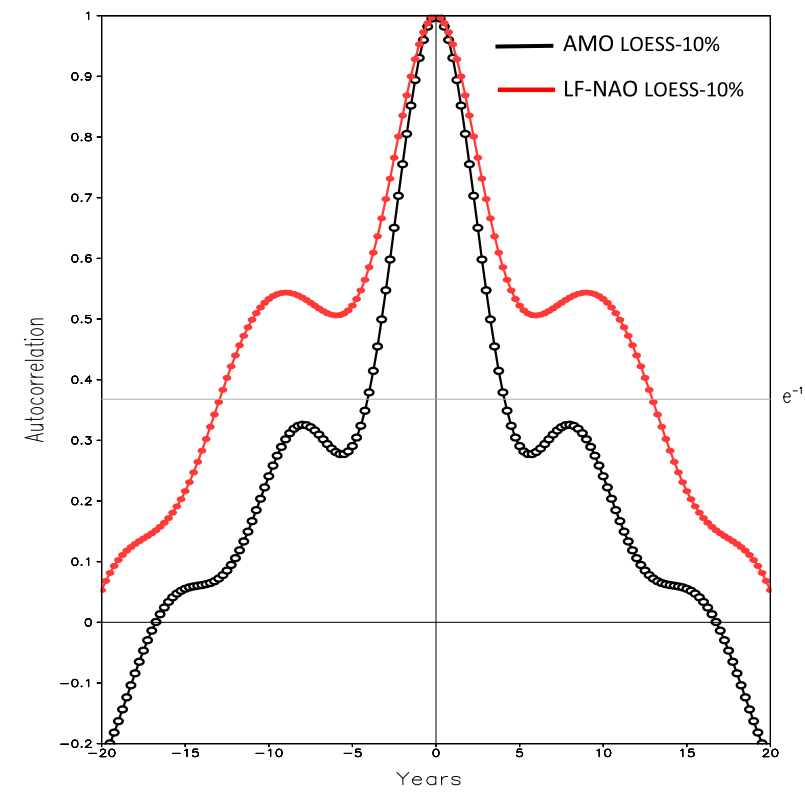

FIG. 7. Atlantic multidecadal variability time scales: Autocorrelation of the AMO (black) and LF-NAO (red) principal components. The autocorrelations were obtained from the LOESS- $10 \%$ smoothed versions of the principal components over 1900-2017.

lag. Such meridional excursions of the Gulf Stream on decadal time scales and their lead-lag relationship with the LF-NAO and AMO's decadal pulses were analyzed by Nigam et al. (2018). ${ }^{5}$ The cold freshwater in the upper layers (0-200 m) just east of the Grand Banks represents leakage of subpolar water through the Newfoundland basin [see Fig. 4, the third column, in Nigam et al. (2018)]. The warm salty anomalies further to the east originate from the Gulf Stream excursion and its sectional detachment (cf. Nigam et al. 2018).

The subsurface temperature and salinity anomalies associated with the Pacific modes (Fig. 8, bottom rows) do not extend as deeply as the Atlantic ones. The PDV-pan Pacific ones are confined to upper layers $(0-200 \mathrm{~m})$, likely from this mode's transect being limited to the tropics and subtropics. The warm salty nature and the modest subsurface reach of the anomalies off Baja California indicate anomalous downwelling as their origin. Southwestward toward the equator in the central Pacific, the upper-layer anomalies are essentially cold and fresh but for the very thin warm layer near the surface. More coherent and deeply extended (up to $\sim 500 \mathrm{~m}$ ) anomalies are

\footnotetext{
${ }^{5}$ Note that the LOESS-10 smoothed SST PCs (Fig. 1, black lines) fully retain the notable decadal pulses present in the raw PCs, and as such, regressions on the smoothed PCs (e.g., Fig. 8) represent, primarily, the structure of decadal variability.
} 

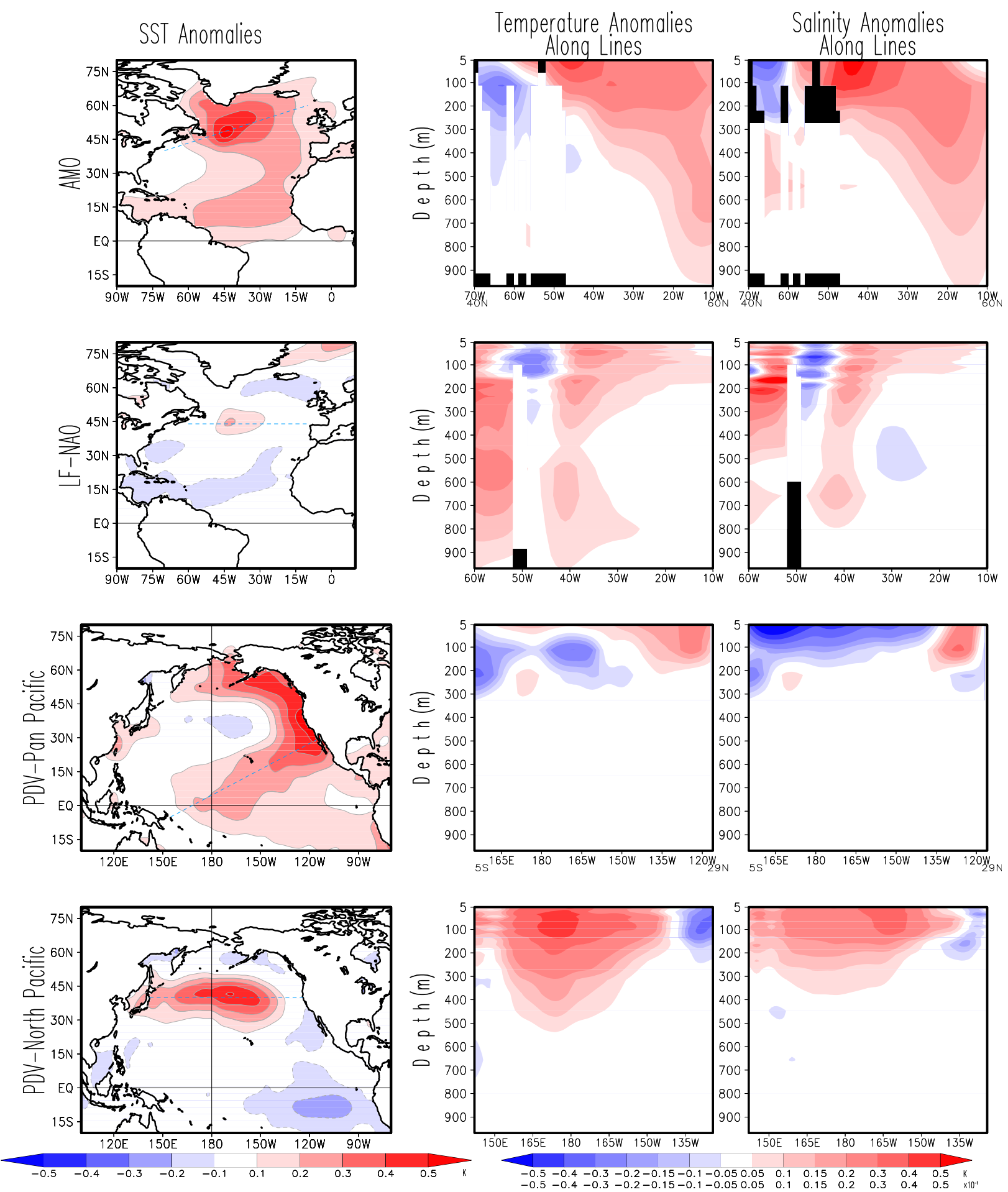

FIG. 8. Subsurface extensions of decadal-to-multidecadal SST variability: Contemporaneous regressions of (left) SST (K), (center) subsurface temperature (K), and (right) salinity $\left(10^{-1}\right)$ on the smoothed (LOESS-10\%) principal components of (top) AMO, (top middle) LF-NAO, (bottom middle) PDV-PP, and (bottom) PDV-NP over 1900-2017. The subsurface structure (in the center and right columns) is along transects marked on the related mature-phase SST regressions (in the left column) using dashed blue lines; the transects intersect regions of maximum sea surface temperature anomalies; subsurface fields are from the EN4.2.1 dataset. Red (blue) shading denotes positive (negative) regressions as per the color bars. The fields are displayed after smoothing from 12 applications of smth9 in GrADS. 
found along the transect bisecting the key feature of the PDV-North Pacific mode. The warm salty anomalies in the central basin with largest amplitude in the near-surface layers and the cold fresh anomalies in near-coastal sector of the eastern basin are consistent with the impact of anomalous anticyclonic atmospheric flow on the underlying ocean. Such circulation would lead to diminished westerlies in the midbasin, reducing heat and moisture fluxes (loss) from the ocean surface, while the related northerlies along the U.S. West Coast would result in increased upwelling (see next section).

\section{Link between multidecadal modes: Intrabasin and interbasin linkages}

The EOF (and extended-EOF) analysis yields principal components that are orthonormal. ${ }^{6}$ All modes, including multidecadal ones, are thus unrelated from the PC correlation perspective. Simultaneous correlationmandated to be zero in this analysis-is however an incomplete measure of linkage, whose assessment requires additional evaluation of the lead-lag correlations.

\section{a. Intrabasin links}

Lead-lag correlations of the AMO and LF-NAO PCs (Fig. 9, top) show the smoothed PCs to be essentially uncorrelated at zero lag. The AMO however lags the LF-NAO by $\sim 6.5$ years, and more robustly by $\sim 16$ years when the lag correlation is 0.70 . The two lead-lag correlation peaks arise from the presence of decadal and multidecadal variability components. The $\sim 6.5$-yr lag of the AMO vis-à-vis LF-NAO was noted also in Nigam et al. (2018), where decadal fluctuations of the subpolar gyre were of interest and zeroed on through regressions on the AMO index tendency rather than the index itself. The longer AMO lag ( $\sim 16$ years $)$-in accord with $\mathrm{Li}$ et al.'s (2013) estimate of 15-20 years from observational analysis-is of considerable interest in the context of multidecadal evolution of Atlantic SSTs and elaborated on after noting the interbasin links.

\section{b. Interbasin links}

Lead-lag links between the key Atlantic and Pacific multidecadal modes are documented in Fig. 9: PDV-NP [or PDO's negative $(-\mathrm{ve})$ phase] leads the negative

\footnotetext{
${ }^{6}$ Rotation of PCs, performed in this analysis, destroys the spatial orthogonality of the related loading vectors (i.e., extended EOFs) but leaves intact the temporal orthogonality of the PCs. The smoothed PCs also remain approximately orthonormal; e.g., the smoothed PDV-NP and PDV-PP PCs are simultaneously correlated at -0.01 .
}
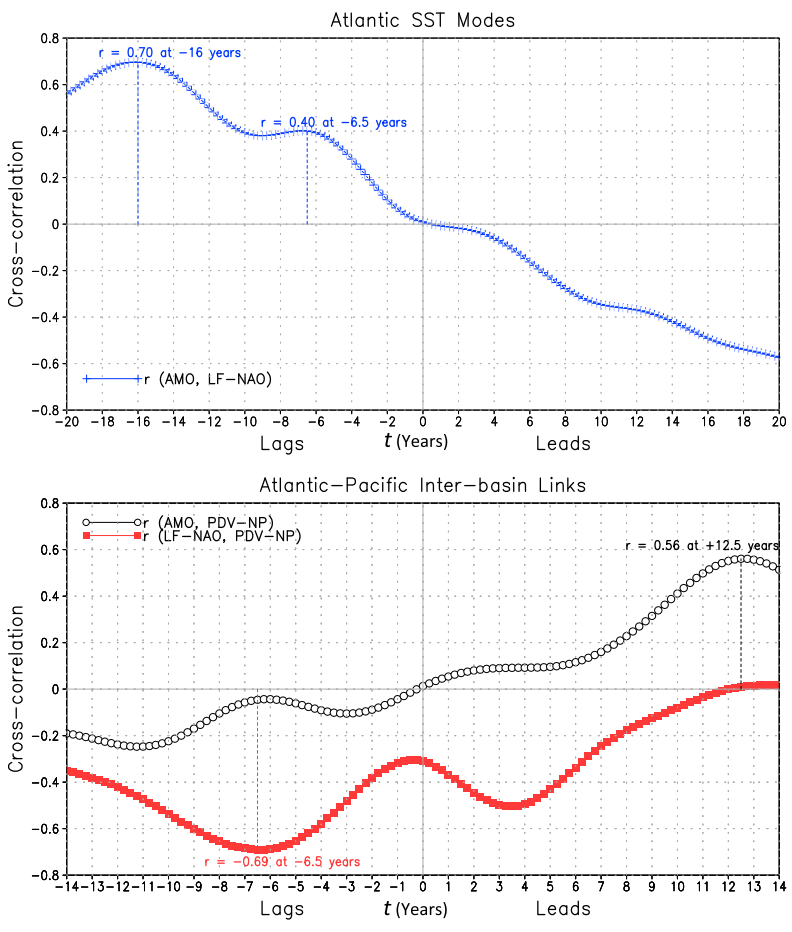

FIG. 9. Intra- and interbasin modal links. (top) Within-Atlantic basin links are documented from the lead-lag cross correlations of the smoothed (LOESS-10\%) AMO and LF-NAO principal components (PCs). (bottom) The Atlantic-Pacific basin links are documented through lead-lag cross correlations of the smoothed AMO and PDV-NP PCs (black) and the smoothed LF-NAO and PDV-NP PCs (red). Note that correlations larger than $|0.33|$ are statistically significant at the $95 \%$ level for the smoothed PCs in both panels, as assessed by a two-tailed Student's $t$ test after factoring for serial correlation [following Metz (1991)]. The plotting convention is as follows: If $r(A, B)>0$ for $t<0, B$ leads $A$; if $r>0$ for $t>0, B$ lags $A$; and if $r<0$ for $t>0, B$ lags $-A$.

phase of LF-NAO by $\sim 6.5$ years (red) whereas AMO leads PDV-NP by $\sim 12.5$ years (black), with correlations of 0.69 and 0.56 , respectively, indicating significant interbasin interaction on multidecadal time scales.

Stated differently, PDV-NP's positive phase precedes the negative phase of LF-NAO by $\sim 6.5$ years, which, in turn, precedes AMO's negative phase by $\sim 16.5$ years. The interbasin interaction loop is closed by noting the AMO's 12.5-yr lead over PDV-NP, which applies to both phases. The positive-to-negative phase evolution of PDV-NP thus takes $\sim 35$ years (= $6.5+16.5+12.5$ ). A $35-y r$ estimate for phase reversal would suggest an $\sim 70$-yr period. The AMO and LFNAO's period would be just as long in this scheme as the interaction loop can begin with these modes too. The estimated period ( $\sim 70$ years $)$ is broadly consistent with the independent estimate based on autocorrelation structure (Figs. 5 and 7), which indicated a $55-80$-yr period range, with PDV-NP ( $~ 55$ years $)$ and 
LF-NAO ( $\sim 80$ years) bracketing the range and AMO $(\sim 70$ years $)$ at its center. Note that some discrepancy in estimation is inevitable due to the shortness of the observed SST record (118 years), which accommodates less than two cycles of multidecadal SST variability in either basin.

Lead-lag correlations of PCs (Fig. 9) are provided a spatiotemporal context in Fig. 10 from the display of SST and SLP regressions on the smoothed PDV-NP, LF$\mathrm{NAO}$, and AMO PCs. The strategy is to temporally sequence the regressions on PDV-NP [over 6 years beginning with its peak positive $(+\mathrm{ve})$ phase; time $\uparrow]$, LFNAO (over 16 years starting with its peak -ve phase; time $\downarrow$ ), and on AMO (over 12 years starting from its peak - ve phase; time $\uparrow$ ) to facilitate direct visual recognition of the PDV-NP's phase reversal; each lag period is set by the lead-lag links identified in Fig. 9.

Lagged regressions of PDV-NP (Fig. 10, left) begin with its peak +ve phase, consisting of a zonal band of warm SST anomalies $(\sim 0.3 \mathrm{~K})$ extending from the coast of Japan to the central-eastern midlatitude Pacific; some differences from its Fig. 2 portrayal stem from the regressions in Fig. 10 being on LOESS-smoothed PCs. Interestingly, Atlantic SSTs are relatively quiescent at this time, but not SLP. In $\sim 6$ years (time $\uparrow$ ), PDV-NP's coherent structure dissipates while the Atlantic SSTs evolve into a triband structure resembling LF-NAO's - ve phase (Fig. 10, top middle). The resemblance is quantified via spatial correlation (0.93) of the Atlantic SST anomalies in the top left and middle panels, corroborating the earlier finding that PDV-NP's peak phase leads $\sim 6$ years later to an opposite-signed LF-NAO peak phase-a Pacific orchestration of North Atlantic SST variability!

Lagged regressions on the negative LF-NAO PC (Fig. 10, middle column; time $\downarrow$ ) broadly show the Pacific SSTs winding down further, becoming nondescript in $\sim 12$ years-a time span over which Atlantic SSTs exhibit phenomenal evolution, beginning with the southward leakage of cold freshwater from the subpolar gyre through the Newfoundland Basin, along the Grand Banks $(t+2$ years $)$ and its subsequent eastward, southeastward, and southwestward expansion into the midlatitude and subtropical basins. At $t+16$ years, SST anomalies in the North Atlantic resemble the mature-phase AMO SST anomalies (cf. Fig. 6, left, but for the sign), ${ }^{7}$ with a lopsided amplitude distribution favoring the subpolar basin. Comparison with simultaneous SST regressions on the negative

\footnotetext{
${ }^{7}$ Fig. 6 shows SST regressions on the unsmoothed PCs, not the LOESS-smoothed PCs used in Fig. 10.
}

AMO PC (Fig. 10, bottom right) indicates broad similarity in the Atlantic (spatial correlation is 0.84), supporting the LF-NAO's 16-yr lead over the AMO (a notable intrabasin link on multidecadal time scale); a leading role for NAO's decadal variations (i.e., LF-NAO) in engendering AMO variability has been noted before (e.g., Latif and Keenlyside 2011; Sun et al. 2015).

Lagged regressions on the negative AMO PC (Fig. 10, right column; time $\uparrow$ ) show gradual diminution of SST anomalies in the Atlantic alongside coherent development in the Pacific. At $t+12$ years, the Pacific SST anomalies resemble the -ve phase of the PDV-NP (or the +ve PDO) while the Atlantic anomalies are anemic; the strong resemblance with PDV-NP is supported by the robust spatial correlation $(-0.92)$ of the Pacific SST anomalies in the left-bottom and top-right panels.

The phase reversal of the multidecadal PDV-NP mode evidently involves Atlantic-leading interbasin interactions along with modal interactions within the Atlantic basin. Such assertions can be made also for the LF-NAO and AMO modes, all indicating the importance of interbasin interactions in the generation of multidecadal SST variability.

\section{c. Interbasin links: Mechanics}

Investigation of the mechanisms generating interbasin linkage is beyond the scope of this observational analysis, for reasons of both space and the climate modeling experiments that would need to be conducted for understanding how regional and remote influences of each basin develop. A brief commentary on related atmospheric circulation (a key link agent) follows, albeit at the surface. The surface focus, through SLP regressions, will limit insights on interbasin signal propagation (best tracked at an upper-tropospheric level; e.g., Chafik et al. 2016) but could indicate how the near-surface ocean is influenced.

Concurrent SLP regressions on the PDV-NP PC (Fig. 10, bottom left) consist of an expansive anticyclone in the Pacific midlatitudes and another over northeastern Canada. The former-the more impressive oneweakens the Aleutian low (and the midlatitude westerlies), and as noted earlier (section 4d), the collocation of the westerly reduction region [where $\partial(\mathrm{SLP}) / \partial y$ is large and +ve] and +ve SST anomalies support the surface flux modulation origin for the Pacific SST anomalies. ${ }^{8}$ In subsequent years, the Aleutian low recovers some

\footnotetext{
${ }^{8}$ Note the small contour interval $(0.05 \mathrm{hPa})$ in SLP regressions, which would lead to $\sim 1 \mathrm{~m} \mathrm{~s}^{-1}$ change in wind speed-small but consequential given the multidecadal time scales (cf. footnote 4).
} 

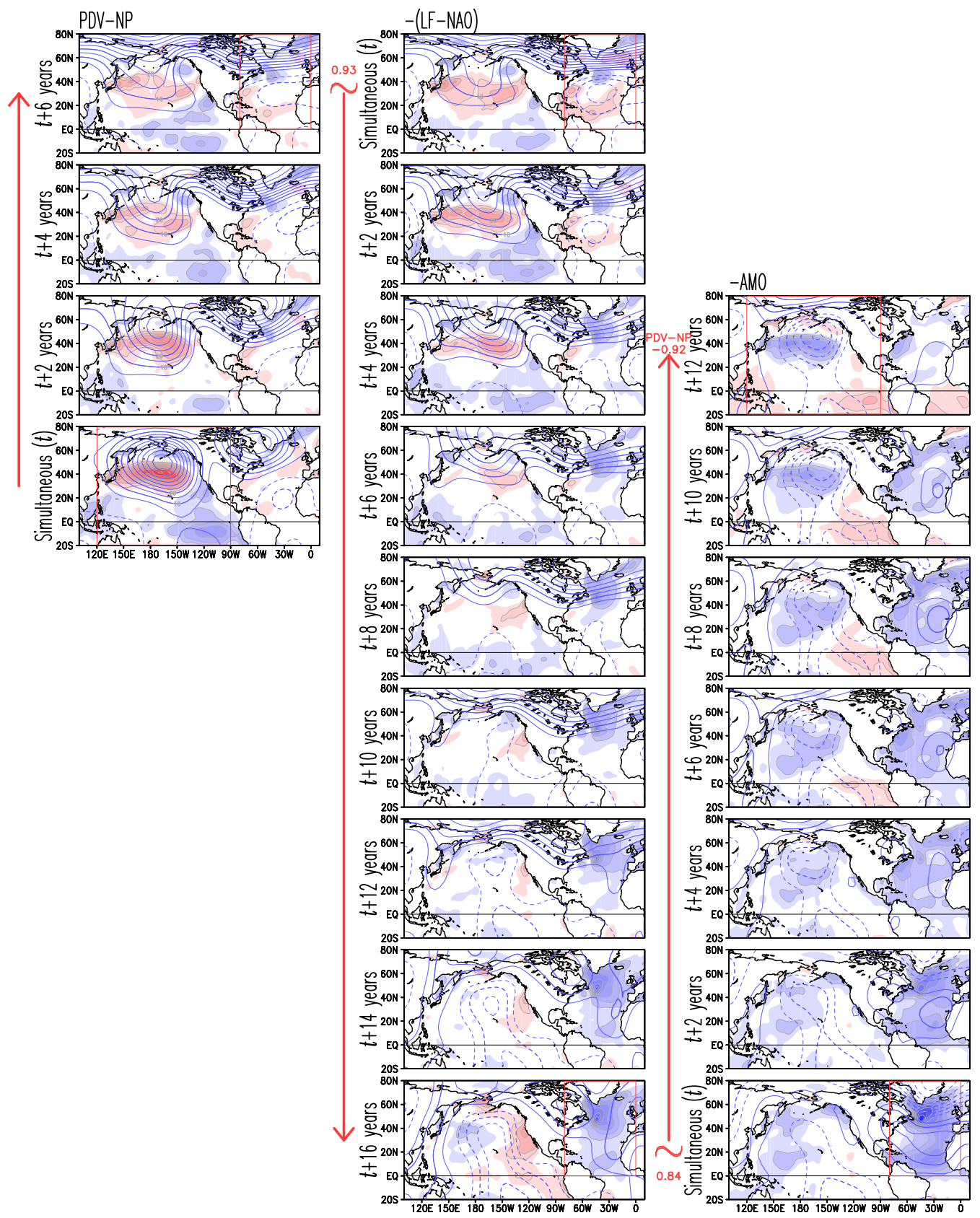

FIG. 10. Basin links manifest in lag regressions of multidecadal PCs: Lagged regressions of SST (shaded) and SLP (contoured) on the smoothed (LOESS-10\%) (left) PDV-NP, (center) negative LF-NAO, and (right) negative AMO PCs over 1900-2017, are shown from the mature phase at 2-yr intervals with red arrows indicating increasing time lag. Red (blue) shading denotes +ve (-ve) SST regressions (K); the shading interval and threshold is $0.05 \mathrm{~K}$. The overlaid solid (dashed) blue contours denote + ve (-ve) SLP regressions at a 0.05-hPa interval. The fields are shown after smoothing from 12 applications of smth9 in GrADS. Note that the 6-yr-lag regressions on PDV-NP (at top left) resemble the mature - ve phase of the LF-NAO (at top middle), as evident from the high spatial correlation (0.93) of the Atlantic SST anomalies (within the red box in both panels). The 16-yr-lag regressions of the negative LF-NAO, on the other hand, resemble the mature negative phase of the AMO (at bottom right), supported by the 0.84 spatial correlation of SST anomalies in the Atlantic domain (red box). Finally, 12-yr-lag regressions of the negative AMO mode (at top right) closely resemble the mature phase of PDV-NP (at bottom left) in the Pacific basin, but for the sign; the resemblance is underscored by the high spatial correlation (-0.92) of the SST anomalies in the Pacific basin (the red box in both panels). It is noteworthy that an initial + ve PDV-NP phase (at bottom left) leads to a -ve PDV-NP phase (at top right), i.e., a phase reversal, after 34 years $(=6+16+12$ lags $)$, from both intra- and interbasin interactions. 
TABLE 1. Sensitivity tests: T0 is the primary analysis while T1-T6 are additional analyses performed for assessment of T0's robustness. Departures from T0 (or its cousins) are enumerated below.

\begin{tabular}{clcr}
\hline \hline Name & \multicolumn{1}{c}{ Domain } & Modes rotated & Width of sampling window \\
\hline T0 & $80^{\circ} \mathrm{N}-20^{\circ} \mathrm{S}, 0^{\circ}-360^{\circ}$ & 11 & 5 seasons \\
T1 & $70^{\circ} \mathrm{N}-20^{\circ} \mathrm{S}, 0^{\circ}-360^{\circ}$ & 11 & 5 seasons \\
T2 & $70^{\circ} \mathrm{N}-20^{\circ} \mathrm{S}, 0^{\circ}-360^{\circ}$ & 10 & 5 seasons \\
T3 & $60^{\circ} \mathrm{N}-20^{\circ} \mathrm{S}, 0^{\circ}-360^{\circ}$ & 11 & 5 seasons \\
T4 & $80^{\circ} \mathrm{N}-20^{\circ} \mathrm{S}, 0^{\circ}-360^{\circ}$ & 11 & 7 seasons \\
T5 & Pacific Ocean $\left(60^{\circ} \mathrm{N}-20^{\circ} \mathrm{S}, 120^{\circ} \mathrm{E}-60^{\circ} \mathrm{W}\right)$ & 7 & 5 seasons \\
T6 & Pacific + Indian Ocean $\left(60^{\circ} \mathrm{N}-20^{\circ} \mathrm{S}, 30^{\circ} \mathrm{E}-60^{\circ} \mathrm{W}\right)$ & 7 & 5 seasons \\
\hline
\end{tabular}

but both it and the Icelandic low remain weaker than normal (e.g., Fig. 10, middle column, top three panels). Interestingly, SLP regressions, with a +ve $\partial(\mathrm{SLP}) / \partial y$ structure over both northern basins, reflect the presence of geostrophic easterly anomalies in the middle-high latitudes, not unlike that in the low phase of the index cycle (e.g., Namias 1950). SST anomalies in the subpolar North Atlantic, unlike those in the Pacific, are not in accord with the surface flux modulation hypothesis (e.g., cold SSTs at $t+2$ and $t+4$ years underlie easterly surface wind anomalies), that is, reduced wind speed regions. This is not altogether surprising given the complex bathymetry (multiple basins and fracture zones) and regional currents in the North Atlantic, which can enhance the contribution of ocean dynamical processes, including advection, in generation of multidecadal variability at the surface and subsurface.

\section{Analysis sensitivity and mode physicality}

\section{a. Sensitivity tests}

The robustness of the identified variability modes, especially multidecadal ones, is assessed by perturbing the primary analysis by changing the analysis domain, the number of modes rotated, and the width of the sampling window. Table 1 lists the sensitivity tests. Test $\mathrm{T} 1$ closely resembles the primary analysis (T0) but for a $10^{\circ}$ southward shift in the analysis domain's northern boundary; the boundary is further shifted southward in T3. Test T2 involves a change in the number of modes rotated (from 11 to 10) vis-à-vis T1. The temporal width of the sampling window is larger (7 seasons) in T4 vis-à-vis T0, to assess if the 5-season window width was adequate for sampling decadalmultidecadal evolution. The analysis domain is restricted to the Pacific basin in T5 and to the Indo-Pacific basin in T6, relative to T3; note, a smaller number of modes are rotated in $\mathrm{T} 5$ and $\mathrm{T} 6$, commensurate with the smaller spatial domain. Sensitivity results are summarized in Table 2 where each mode of the primary analysis (T0) is compared with its perturbed counterpart; the correlation of PCs, variance explained, and the corresponding rank are all tabulated. Key findings are the following:

- Low sensitivity to modest variations in the analysis domain's northern boundary, which is at $80^{\circ} \mathrm{N}$ in $\mathrm{T} 0$,

TABLE 2. Sensitivity results: Column 1 lists the 11 variability modes obtained in the primary analysis (T0). The number following each mode is the percentage variance explained by it, and the subsequent number is its rank. The number in parentheses in the top row is the total percentage variance explained by all modes in that analysis. Columns $2-7$ list modal features, with the three slash-delimited numbers denoting correlation between the unsmoothed principal component of the test case (T1-T6) and the primary analysis (T0) over the full period (1900-2018), the percentage variance explained by that mode, and its rank in the test analysis, respectively. Dashed spaces indicate "not applicable.",

\begin{tabular}{|c|c|c|c|c|c|c|}
\hline Т0 (60.9) & T1 (61.9) & $\mathrm{T} 2(60.7)$ & T3 (62.8) & T4 (58.6) & T5 (64.5) & T6 (62.1) \\
\hline Trend/16.4/1 & $0.99 / 15.7 / 1$ & 0.99/16.0/1 & $0.99 / 15.6 / 1$ & $0.98 / 17.1 / 1$ & $0.96 / 11.9 / 3$ & $0.96 / 16.1 / 2$ \\
\hline ENSO decay/12.8/2 & $0.99 / 13.2 / 2$ & $0.99 / 13.3 / 2$ & $0.99 / 13.6 / 2$ & $0.77 / 8.8 / 3$ & 0.99/18.9/1 & $0.99 / 17.0 / 1$ \\
\hline ENSO growth/10.1/3 & $0.99 / 10.4 / 3$ & $0.99 / 10.4 / 3$ & $0.99 / 10.7 / 3$ & $0.75 / 6.8 / 4$ & $0.99 / 15.4 / 2$ & $0.99 / 13.4 / 3$ \\
\hline PDV-PP/4.2/4 & $0.99 / 4.4 / 4$ & $0.98 / 4.4 / 4$ & $0.99 / 4.5 / 4$ & $0.95 / 3.6 / 5$ & $0.95 / 6.8 / 4$ & $0.94 / 5.5 / 4$ \\
\hline $\mathrm{AMO} / 3.4 / 5$ & $0.99 / 3.6 / 6$ & $0.94 / 3.5 / 6$ & $0.99 / 3.6 / 6$ & $0.97 / 3.1 / 6$ & - & - \\
\hline Atlantic Niño/3.3/6 & $0.99 / 3.6 / 5$ & $0.99 / 3.5 / 5$ & $0.99 / 3.7 / 5$ & $0.95 / 2.4 / 8$ & - & - \\
\hline PDV-NP/2.7/7 & $0.99 / 2.8 / 7$ & $0.99 / 2.8 / 7$ & $0.99 / 2.8 / 7$ & $0.83 / 2.7 / 7$ & $0.92 / 4.3 / 5$ & $0.88 / 3.8 / 5$ \\
\hline Biennial/2.6/8 & $0.99 / 2.7 / 8$ & $0.98 / 2.7 / 8$ & $0.99 / 2.7 / 8$ & $0.47 / 1.7 / 10$ & $0.94 / 3.5 / 7$ & $0.95 / 3.2 / 6$ \\
\hline ENSO-NC/2.3/9 & $0.99 / 2.4 / 9$ & $0.99 / 2.3 / 9$ & $0.99 / 2.4 / 9$ & $0.58 / 1.8 / 9$ & $0.94 / 3.7 / 6$ & $0.94 / 3.1 / 7$ \\
\hline LF-NAO/1.7/10 & $0.98 / 1.6 / 10$ & $0.97 / 1.8 / 10$ & $0.93 / 1.8 / 10$ & - & - & - \\
\hline Sub-Arctic DV/1.4/11 & $0.98 / 1.5 / 11$ & - & $0.86 / 1.4 / 11$ & $0.83 / 1.3 / 11$ & - & - \\
\hline
\end{tabular}


$70^{\circ} \mathrm{N}$ in $\mathrm{T} 1$, and $60^{\circ} \mathrm{N}$ in $\mathrm{T} 3$. The PC correlation and explained variance are almost identical in $\mathrm{T} 0$ and $\mathrm{T} 1$. T0 was chosen as the primary analysis to fully resolve variations of the subpolar gyre along with its current systems. Test $\mathrm{T} 3\left(60^{\circ} \mathrm{N}\right.$ boundary) results are very close to T0's except for the representation of subArctic variability - understandably, in view of T3's curtailed northern domain. Note that the total amount of explained variance increases with decreasing domain size for the same number of modes, as expected.

- Low sensitivity to the number of modes rotated: 10 are rotated in $\mathrm{T} 2$ as opposed to 11 in $\mathrm{T} 1$, their only difference. PC correlations with T0's are between 0.97 and 0.99 except for one at 0.94 , and variance explained by the 10 leading modes is close: 60.7 in T2 versus $60.4(=61.9-1.5)$ in $\mathrm{T} 1$, indicating that the 10 leading modes are essentially unchanged, or robust.

- Sampling window sensitivity: Tests T0 and T4 differ only in the sampling window-width, with T4's being larger ( 7 seasons). Immediately noted are the modest correlations $(0.47-0.77)$ of interannual modes (ENSO growth and decay, non-canonical ENSO, and biennial variability); T4's second-leading mode is most correlated with T0's ENSO growth (0.57) but T4's fourth mode is even more correlated with this mode $(0.75)$, as noted in the table. The trend and decadal-to-multidecadal modes fare better, with correlations in the $0.83-0.98$ range but T0's LF-NAO has no counterpart in T4. Additional analysis revealed that wider sampling was overkill in the interannual context, with oversampling leading to ENSO growth's capture as two modes and aliased representation of the others. This misrepresentation is not without collateral damage in the decadal-tomultidecadal realm; T0's five-season window is more optimal.

- The Pacific basin analysis (T5) is very similar to that of GN2008 but for the updated dataset period. The T5 and the Indo-Pacific basin analysis (T6) PC correlations with $\mathrm{T} 0$ are in the $0.92-0.99$ and $0.88-0.99$ range, respectively; the weakest correlation in both cases is for the PDV-NP mode (0.92 and 0.88, respectively). That this of all the Pacific modes is impacted the most by the inclusion of the Atlantic basin (T0), indirectly, attests to the significance of interbasin links in PDVNP's evolution.

\section{b. Mode physicality}

Assessing the physicality of modes-their physical realizability-is an important step after the mathematical/
TABLE 3. Number of observational analogs present in various (T0-T6) analyses of seasonal SST variability during the period 1900-2018. An analog is deemed to occur when the absolute value of the unsmoothed principal component (PC) of any one mode is larger than that of all others by at least one unit in that season; note the PCs are orthonormal. Mathematically, if || $\mathrm{PC}_{i}(t)|-| \mathrm{PC}_{j}(t)||>$ 1.00 for all $j$ not equal to $i$, an analog is counted at time $t$.

\begin{tabular}{llllllll}
\hline \hline & T0 & T1 & T2 & T3 & T4 & T5 & T6 \\
\hline Analog count & 37 & 38 & 31 & 52 & 31 & 44 & 42 \\
\hline
\end{tabular}

statistical analysis that yields the modes. These analyses identify optimal structures that succinctly (i.e., efficiently) capture variance but with no assurance that such optimal structures are realizable/realized. A straightforward test of physicality is scanning the observed (or simulated) variability structures for modal analogs. Indirect tests are based on correlations with related but independently gathered/analyzed data. Both have been used in assessing the physicality of the SST variability modes [e.g., Mantua et al. (1997), who pioneered the use of fish recruitment in such assessments, and GN2008, who used both analogs and fish recruitment data].

\section{1) OBSERVATiOnal AnAlogs}

A mode is deemed to have an observational analog if the observed anomaly at any time strongly resembles the modal structure (i.e., the observed anomaly can be largely accounted for by the expression of just one mode). More formally, an observed anomaly is deemed to be a modal analog if any one of the PCs is much larger than all the rest at that time. The analog count-the total number of observational analogs in the analysis period-is a useful measure of the overall physicality of the analysis. Table 3 lists the number of observational analogs in the primary (T0) and perturbed analyses (T1-T6). The number depends on the domain size, with more analogs found in smaller domains ( $\mathrm{T} 1$ and $\mathrm{T} 3$ vs T0; T5 vs T6). The analog count will, of course, be smaller with fewer modes (T2 vs T1). T0 has 37 analogs, fewer than in T1 and $\mathrm{T} 3$, but $\mathrm{T} 0$ was chosen as the primary analysis because its more northern boundary resolves subpolar variability.

\section{2) CORRElations With FISH RECRUITMENT}

Fish recruitment provides a unique assessment of mode physicality, especially for the decadal-tomultidecadal SST variability modes, which can influence marine ecosystems. The North Pacific and the 
TABLE 4. Correlations of the unsmoothed principal components (PCs) of the Pacific and Atlantic multidecadal SST variability modes from the primary analysis (T0) with selected fish recruitment (FR) records. The FR source is noted in the related footnote while the period is listed next to its name. All time series, including PCs, are annually resolved here. The two highest correlations for each decadal-tomultidecadal mode are in bold.

Multidecadal PCs and variability indices

FR

No. Fish recruitment record

PDV-NP PC PDO index PDV-PP PC NPGO index AMO PC AMO index LF-NAO PC

1 Eastern Pacific zooplankton biomass (40); ${ }^{\mathrm{a}}$ 1965-97

2 British Columbia coho salmon catch (67); ${ }^{\mathrm{a}} 1965-97$

3 British Columbia pink salmon catch (68); ${ }^{\mathrm{a}}$ 1965-97

4 Gulf of Alaska halibut recruitment (43); ${ }^{\mathrm{a}}$ 1965-97

5 West Coast mackerel recruitment (81); ${ }^{\mathrm{a}}$ 1965-97

6 Central Alaska chinook catch (51); ${ }^{\mathrm{a}}$ 1965-97

7 Eastern Bering Sea rock sole recruitment (20); ${ }^{\mathrm{a}}$ 1965-97

8 Central Alaska pink catch (54); ${ }^{\mathrm{a}}$ 1965-97

9 Regulatory area 3B halibut catch, IPHC; ${ }^{\mathrm{b}}$ 1991-2014

10 Regulatory area 4A halibut catch, IPHC; ; 1991-2014

11 Regulatory areas 3B and 4A combined catch, IPHC; 1991-2014

12 IPHC coastwide model; 1925-2010

13 IPHC areas-as-fleets model; ${ }^{c}$ 1925-2010

14 Norwegian spring-spawning herring, ;,e $1907-2010$

15 Atlantic mackerel (Canadian landings); ${ }^{\mathrm{f}, \mathrm{g}, \mathrm{h}}$ 1901-2016

16 Atlantic mackerel (U.S., Canada, foreign landings); ${ }^{\mathrm{g}, \mathrm{h}}$ 1960-2016

\begin{tabular}{|c|c|c|c|c|c|c|}
\hline-0.19 & 0.10 & 0.20 & 0.32 & 0.46 & 0.23 & -0.21 \\
\hline 0.03 & -0.17 & -0.42 & 0.32 & -0.28 & -0.19 & -0.33 \\
\hline-0.12 & -0.13 & -0.24 & 0.32 & -0.13 & 0.07 & 0.01 \\
\hline-0.76 & 0.73 & 0.11 & 0.37 & -0.07 & 0.06 & 0.41 \\
\hline-0.63 & 0.66 & 0.36 & 0.12 & 0.05 & 0.14 & 0.55 \\
\hline-0.41 & 0.59 & 0.38 & -0.12 & -0.16 & 0.24 & 0.76 \\
\hline-0.42 & 0.67 & 0.34 & -0.18 & 0.43 & 0.52 & 0.27 \\
\hline-0.45 & 0.67 & 0.61 & -0.14 & 0.26 & 0.38 & 0.56 \\
\hline-0.41 & -0.12 & -0.35 & 0.51 & 0.17 & 0.26 & -0.51 \\
\hline-0.50 & -0.05 & -0.20 & 0.54 & 0.13 & 0.25 & -0.28 \\
\hline-0.45 & -0.10 & -0.33 & 0.53 & 0.17 & 0.26 & -0.48 \\
\hline-0.41 & 0.39 & -0.05 & 0.11 & -0.21 & -0.16 & 0.18 \\
\hline-0.45 & 0.39 & -0.11 & 0.15 & -0.07 & -0.04 & 0.21 \\
\hline 0.28 & -0.28 & - & - & 0.54 & 0.57 & -0.20 \\
\hline-0.11 & 0.06 & - & - & -0.15 & -0.02 & -0.10 \\
\hline 0.11 & -0.27 & - & - & -0.53 & -0.54 & -0.32 \\
\hline 0.20 & -0.06 & - & - & -0.15 & -0.09 & -0.24 \\
\hline 0.08 & 0.27 & - & - & -0.75 & -0.70 & 0.19 \\
\hline
\end{tabular}

18 Gulf of Maine cod; $1982-2013$

${ }^{\text {a }}$ Hare and Mantua (2000); the number following the name in FR1-8 is the original dataset tag and is listed for reference.

${ }^{\mathrm{b}}$ Kong et al. (2004); FR data come from the International Pacific Halibut Commission (IPHC) regulatory areas.

${ }^{\mathrm{c}}$ Stewart and Martell (2014); FR data obtained from the two IPHC models.

${ }^{\mathrm{d}}$ Toresen and Østvedt (2000).

e ICES (2011): Report of the working group on widely distributed stocks (WGWIDE).

${ }^{\mathrm{f}}$ NEFSC (1996): 20th Northeast regional stock assessment workshop report.

${ }^{g}$ NEFSC (2006): 42nd Northeast regional stock assessment workshop report.

${ }^{\mathrm{h}}$ NEFSC (2018): 64th Northeast regional stock assessment workshop report.

${ }^{\mathrm{i}}$ SEDAR (2015): Atlantic menhaden stock assessment report.

${ }^{j}$ Palmer (2014): Assessment update report of the Gulf of Maine cod stock.

Bering Sea recruitment records of Hare and Mantua (2000) for the 1965-97 period were augmented and new ones assembled for the North Atlantic basin (cf. section 2e). Their correlations with the Pacific (PDV-PP, PDV-NP) and Atlantic (AMO, LF-NAO) modes are listed in Table 4, along with those of the widely used multidecadal SST variability indices (e.g., PDO and AMO).

The PDV-NP is most strongly correlated $(-0.76)$ with the Gulf of Alaska halibut (FR4), and then with West 


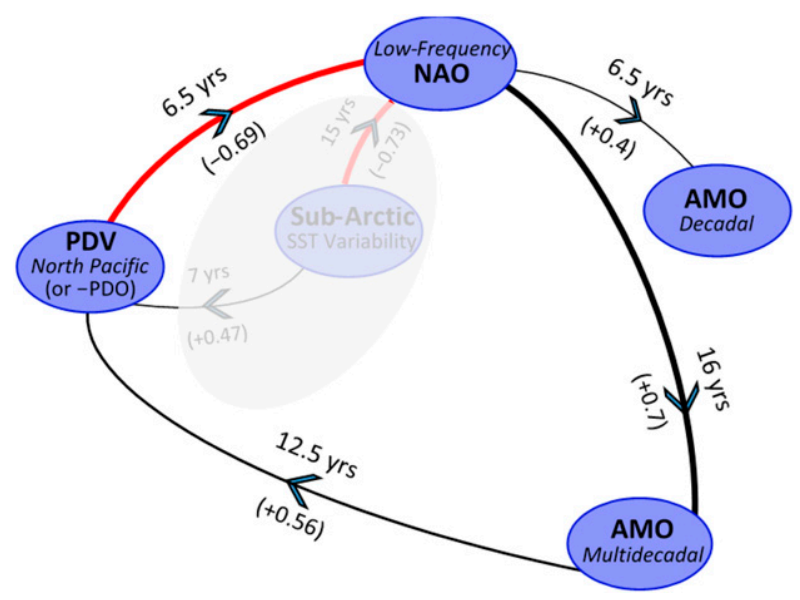

FIG. 11. Schematic of intra- and interbasin interactions: Spatiotemporal analysis of global SST variations during 1900-2017 reveals the Pacific and Atlantic basins to be linked. A black (red) line connects similar (opposite) phases of the lead-lagged modes, with line thickness reflecting, qualitatively, the lag-correlation strength. Note that one or an odd number of red-line links in a closed loop indicates phase reversal, permitting cycling through both phases of all the linked modes. For example, the +ve phase of PDV-NP evolves in the Atlantic basin into a - ve LF-NAO in 6.5 years, which in the following 16 years evolves into a -ve AMO; interestingly, the - ve AMO evolves in the Pacific basin into a - ve PDV-NP (i.e., a full clockwise cycle leads to a phase reversal of PDV-NP). The phase-reversal time (about 35 years, obtained by summing, clockwise, the lags in the main loop) would be the same for the LF-NAO, AMO, and the PDV-NP modes in this scheme. The spatiotemporal analysis of SST variations also yielded the sub-Arctic mode, which was lowest ranked in terms of explained variance, and whose evolution is thus not documented. Although its interactions are indicated in the schematic, they are not the focus as the origin of this high-latitude SST variability mode remains enigmatic. The schematic also depicts, outside of the main loop, an LF-NAO-to-AMO transition over 6.5 years related to AMO's decadal pulses, several of which populate each of its multidecadal phases. This 6-7-yr lag is fully consistent with the findings reported in Nigam et al. (2018) on the evolution and phase reversal of AMO's decadal pulses.

Coast mackerel $(-0.63$, FR5 $) ;{ }^{9}$ corresponding PDO correlations are 0.73 and 0.66 . Longer recruitment records such as FR12-13 (each 96 years as opposed to the 33-yr-long FR4-5) are preferred in assessments of multidecadal variability, ${ }^{10}$ yielding PDV-NP correlations of -0.41 and -0.45 , and PDO ones of 0.39 . Correlations with both short and long recruitment records reveal that the PDV-NP PC is at least as good a

\footnotetext{
${ }^{9}$ GN2008's PDV-NP correlations with FR4 and FR5 were -0.74 and -0.73 , respectively, for the same 33 -yr period.

${ }^{10}$ These longer records (from models) differ significantly in the early period when within-model standard deviation is as large as half of the signal in some years, limiting their utility in physicality assessment.
}

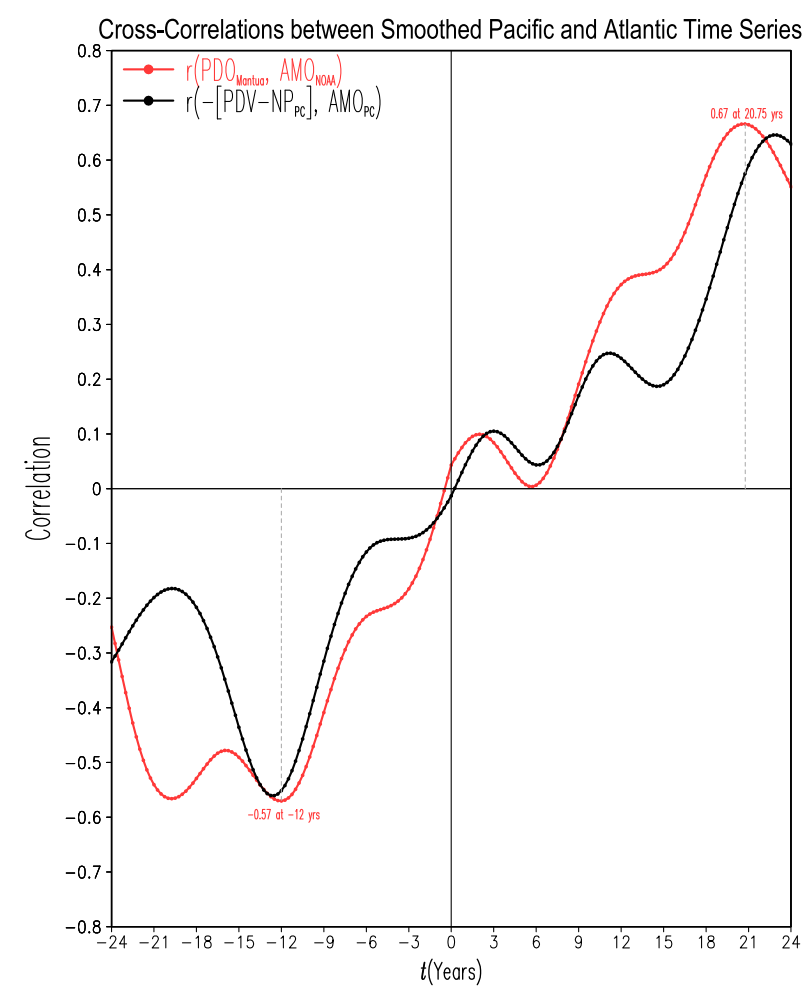

FIG. 12. Lead-lag cross correlations of the smoothed (LOESS10\%) Pacific decadal oscillation index (PDO; Mantua et al. 1997) and the Atlantic multidecadal oscillation index (AMO-NOAA; Enfield et al.2001) are in red, while those of the corresponding SST principal components (PCs) - AMO and the negative PDV-NP - both similarly smoothed, are in black; correlations were computed over 1900-2017 and displayed using a lead-lag convention noted in Fig. 9. The positive correlation peak $(\sim 0.67)$ at $t \approx 21$ years implies that the PDO leads the AMO by 21 years (much as in Figs. 10 and 11) while the negative peaks $(\sim-0.57)$ imply that the AMO's negative phase leads the PDO by 12 (and 19) years; the 12-yr lead was noted in Figs. 10 and 11 but not the 19-yr one. Lead-lag correlations of the PCs are similar to those of the indices but for notable differences when $t<-12$ years; in particular, the PCs do not support the indicesbased finding of a 19-yr lead of AMO's negative phase over the PDO. Note that correlations larger than $|0.34|$ and $|0.33|$ are statistically significant at the $95 \%$ level in the red and black curves, respectively, as assessed by a two-tailed Student's $t$ test after factoring for serial correlation [following Metz (1991)].

marker of marine ecosystem variations as the PDO-and a preferred one, perhaps, in view of its temporal orthonormality with other PCs at zero lag.

The PDV-PP PC exhibits highest correlation with the central Alaska pink catch $(0.61 ;$ FR8) and then with British Columbia Coho salmon ( -0.42 ; FR2), both with 33-yrlong records. The NPGO - a close cousin of the PDV$\mathrm{PP}-$ is however weakly correlated with the FR8 $(-0.14)$ and FR2 (0.32) records. The NPGO does exhibit a higher correlation (0.54) with FR10 (i.e., catchment in the eastern Aleutians) but this record is even shorter (24 years). 

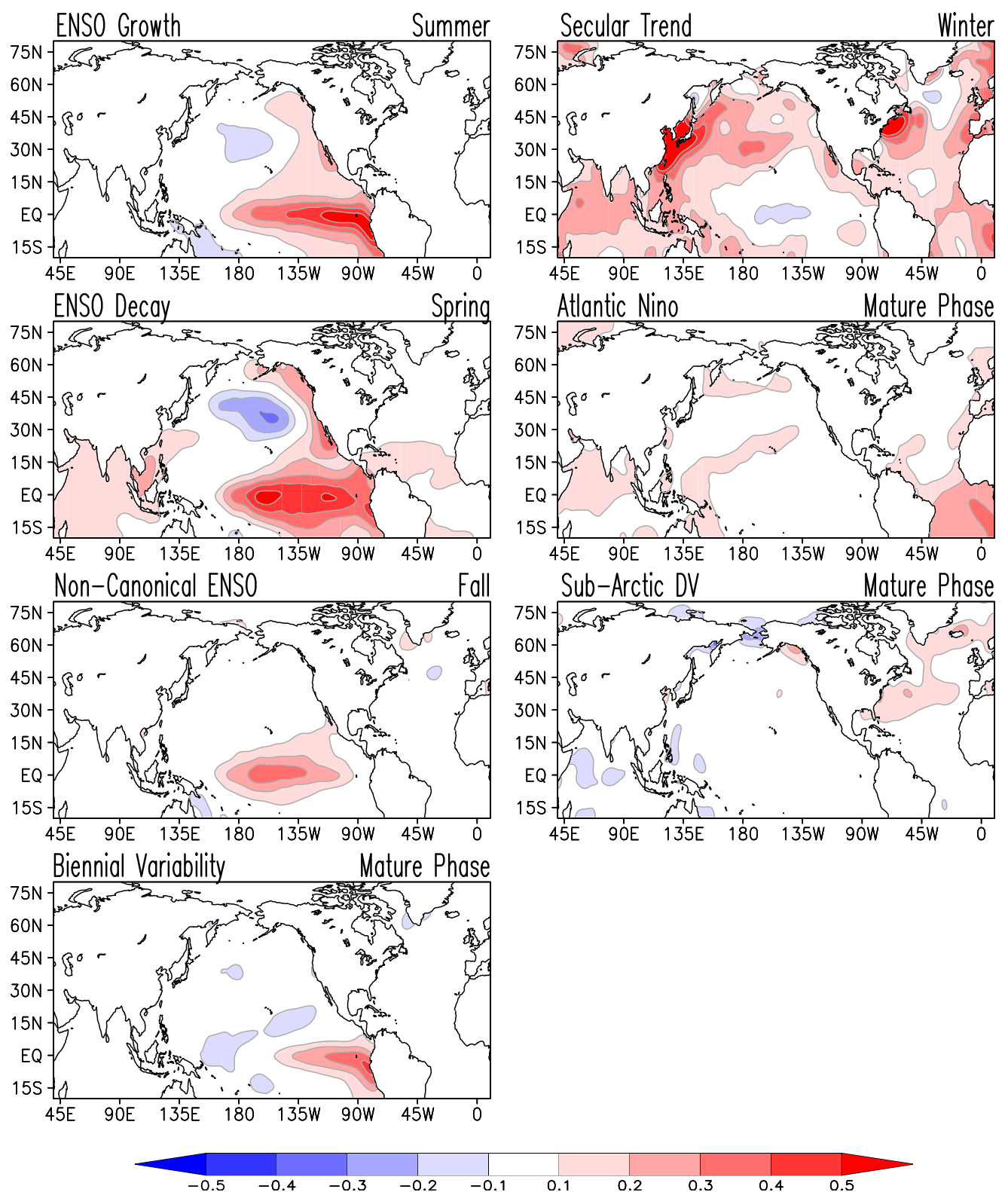

FIG. A1. Mature phase structure of the SST variability modes not displayed in the main section: (left) The ENSO modes (canonical ENSO growth and ENSO decay, non-canonical ENSO, and biennial variability) and (right) SST secular trend, Atlantic Niño, and sub-Arctic decadal variability. The contemporaneous regressions of seasonal SST anomalies on the PCs over 1900-2017 define the mature phase. The mature phase's seasonal preference, if any, is noted in the upper right. Red (blue) shading denotes positive (negative) SST anomalies and the zero contour is suppressed. The contour interval and shading threshold is $0.1 \mathrm{~K}$. The fields are displayed after 12 applications of smth9 in GrADS.

The AMO PC and the AMO index (Enfield et al. 2001) are strongly correlated with the Gulf of Maine cod (FR18), at -0.75 and -0.70 , respectively, but the record is only 32 years long. The PC and the index are similarly and reasonably correlated $(-0.53$ and -0.54$)$ with Atlantic mackerel (FR16) whose record is longer (57 years). The longest recruitment record in Table 4 is for the Norwegian spring-spawning herring (FR14; 104 years) and it is correlated with the PC and index at 0.54 and 0.57 , respectively.

Interbasin links are also manifest in Table 4:

- The AMO exhibits reasonable correlations with Pacific fisheries-for example, its PC is correlated with eastern Pacific zooplankton biomass (FR1) at 0.46 and the AMO index with eastern Bering Sea rock sole recruit- 
ment (FR7) at 0.52 - and not unexpectedly (cf. Fig. 6, middle-left panel).

- PDV-NP and the PDO index are likewise correlated with Norwegian spring-spawning herring (FR14) at 0.28 ; while smaller, the correlation is from a 3-timeslonger record and thus notable.

- Finally, and interestingly, the LF-NAO's strongest correlations with recruitment are found in the Pacific, with central Alaska chinook catch (FR6, 0.76) and pink catch (FR8, 0.56); the strongest Atlantic basin correlation is with mackerel (FR 16, -0.32). LF-NAO's links with Pacific recruitment are not surprising given its substantial Pacific footprint (cf. Fig. 6, right).

\section{Concluding remarks}

The Pacific and Atlantic basins are found linked in the context of multidecadal variations of sea surface temperature.

Across basins, the two prominent Atlantic modes-the Atlantic multidecadal oscillation (AMO) and lowfrequency North Atlantic Oscillation (LF-NAO) - are found linked to the key Pacific multidecadal mode, North Pacific decadal variability (PDV-NP; resembling PDO's - ve phase). The AMO leads PDV-NP by $\sim 12.5$ years [consistent with Zhang and Delworth (2007), d'Orgeville and Peltier (2007), and Marini and Frankignoul (2014)] while the LF-NAO lags the opposite phase of PDVNP by $\sim 6.5$ years (a new finding?). The development of notable sea level pressure regressions in the other basin in Figs. 6 and 10 is indicator of these basin links.

Within the Atlantic basin, the AMO lags LF-NAO by $\sim 16$ years, consistent with the findings of Li et al. (2013).

The intra- and interbasin links are schematically summarized in Fig. 11. The black (red) connecting lines in the main loop link similar (opposite) phases of the lead-lagged modes. One (or an odd number) of the red-line links in a closed loop leads to phase-reversal, permitting cycling through both phases of all the linked modes. For example, the +ve phase of PDV-NP (resembling PDO's - ve phase) and its Atlantic vestiges evolve into a - ve LF-NAO in 6.5 years, which in the following 16 years evolves into a -ve AMO; interestingly, the - ve AMO (and its Pacific footprints) evolves in the Pacific basin into a -ve PDV-NP; that is, a full clockwise cycle leads to the phase reversal of PDV-NP! The related interbasin evolutions of SST and SLP (Fig. 10) indicate a role for both intrabasin processes and interbasin interactions in the phase reversal of the PDV-NP.

One could, similarly, have commenced with the +ve phase AMO in Fig. 11 and cycled clockwise to AMO's - ve phase, transitioning through the + ve PDV-
NP and - ve LF-NAO states; that is, AMO's phase reversal involves more than just intrabasin interactions, which have figured prominently in other phase-reversal hypotheses (e.g., Sun et al. 2015). The phase-reversal time-about 35 years, obtained by summing, clockwise, the lags in the main loop-would be the same for the LF-NAO, AMO, and the PDV-NP modes in this scheme. ${ }^{11,12}$

The $b i$-directional interbasin interactions between three modes outlined in Fig. 11 frame a new perspective on the cycling of multidecadal SST variability. The evidence for a Pacific-basin-leading link with Atlantic SSTs (PDV-NP $\rightarrow$ LF-NAO) - presented, perhaps, for the first time-closes the loop on the cycling of multidecadal variability. The loop is closed by the complementing of two uni-directional interactions documented earlier and corroborated in this analysis: The first, an inter-basin one (AMO $\rightarrow$ PDO), was noted by Zhang and Delworth (2007), d'Orgeville and Peltier (2007), and Marini and Frankignoul (2014), among others. The second, an intra-basin one (LF-NAO $\rightarrow$ AMO), was noted by Li et al. (2013) and Sun et al. (2015). The triadinteraction model (Fig. 11) obviates the need for the quadrature relationship among modes required for the cycling of variability in a two-mode model.

The interbasin links become evident when the modal linkage is investigated using measures that look beyond contemporaneous correlation-a commonly used metric - which, interestingly, is mandated to be zero in principal component (PC) analysis, the PC rotations notwithstanding. The notable lead-lag correlations of the PCs and lead-lag regressions of SST and SLP on these PCs build the case for interbasin links in climate observations.

The interbasin links noted above are not an artifact of the statistical technique used in analysis of spatiotemporal variability. For one, the obtained PCs are vetted from intercomparisons with widely used related indices (e.g., PDO, AMO) and from physicality assessments using fish recruitment records. The interbasin links are, moreover, patent in the lead-lag correlations of the widely used AMO-NOAA (Enfield

\footnotetext{
${ }^{11}$ The spatiotemporal analysis of SST variations also yielded the sub-Arctic mode, which was lowest ranked in terms of explained variance, and whose evolution is thus not documented. Although its interactions are indicated in the schematic, they are not the focus as the origin of this high-latitude SST variability mode remains enigmatic.

${ }^{12}$ Figure 11 also depicts, outside of the main loop, a same-phase LF-NAO-to-AMO transition over 6.5 years related to AMO's decadal pulses, several of which populate each of its multidecadal phases. This $6-7-y r$ lag is consistent with the findings of Nigam et al. (2018) on the evolution and phase reversal of AMO's decadal pulses.
} 

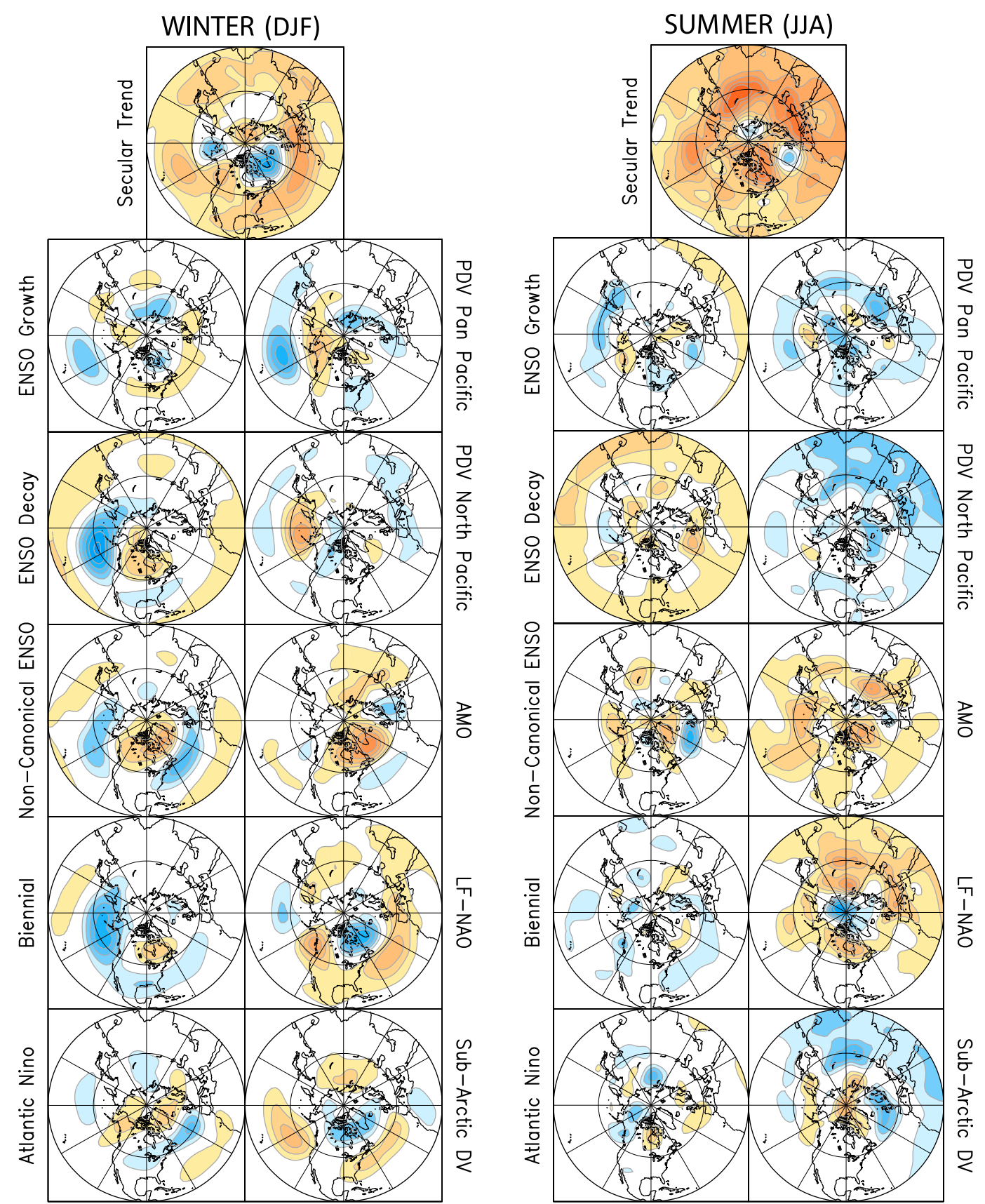

FIG. A2. Atmospheric extensions of SST variability: Contemporaneous regressions of (left) winter (DecemberFebruary) and (right) summer (June-August) seasonal 500-hPa geopotential height (from NCEP reanalysis; Kalnay et al. 1996) on the 11 SST principal components (cf. Fig. 1) over 1949-2015. Orange (blue) shading denotes positive (negative) height anomalies and the zero contour is suppressed. The contour interval and shading threshold is $5 \mathrm{~m}$ in winter and $2.5 \mathrm{~m}$ in the summer.

et al. 2001) and PDO (Mantua et al. 1997) indices (Fig. 12; see also Marini and Frankignoul 2014), which are completely independent of the present analysis; lead-lag correlations of related PCs are in black with PDV-NP's sign flipped to facilitate comparison. The simultaneous correlation of the PCs (and even indices) is near zero, suggesting a lack of relationship. Evaluation of the lead-lag correlations, however, suggests otherwise: the positive peak $(\sim 0.67)$ at $t \approx 21$ years suggests that PDO leads the AMO by 21 years 
(much as in Figs. 10 and 11) while the negative peaks ( - 0.57) suggest that AMO's negative phase leads PDO by 12 (and 19) years. ${ }^{13}$

Other noteworthy findings include the following:

- Subsurface temperature and salinity anomalies linked with multidecadal SST variability extend deeper (to $\sim 1000 \mathrm{~m}$ ) in the Atlantic than in the Pacific; PDVNP's extensions reach only $\sim 450 \mathrm{~m}$ while PDV-PP's are even shallower $(\sim 300 \mathrm{~m})$.

- SST anomalies of the Pan-Pacific decadal mode (PDV-PP; identified by GN2008) are similar to the horseshoe-shaped, coastally focused SSTs associated with the North Pacific Gyre Oscillation (NPGO; Di Lorenzo et al. 2008), the second leading EOF of the modeled sea surface height variations in the extratropical basin. Despite this similarity, connections between the two have remained largely uninvestigated in the past decade.

The Achilles heel of the above findings is the shortness of the observed SST record, which presently accommodates less than two cycles of multidecadal variability. While this has not stopped pursuits to characterize the surface/ subsurface structure of the PDO and AMO since the late 1990s (when observed records were even shorter), our finding on Pacific-Atlantic basin links will need reassessment until such time we have multiple multidecadal cycles in the record. Unfortunately, climate models (at least, the IPCC-AR5 genre) were unable to generate realistic spatiotemporal expressions of multidecadal variability in the Atlantic basin (e.g., Kavvada et al. 2013), precluding the use of this model class in studying interbasin links and their underlying mechanisms.

Acknowledgments. The authors gratefully acknowledge the support of the U.S. National Science Foundation through Grant AGS 1439940. Agniv Sengupta thanks India's National Monsoon Mission, the U.S. National Science Foundation, and the University of Maryland's Graduate School for supporting his doctoral studies, the latter through the Ann Wylie Dissertation Fellowship. The authors thank the reviewers and Editor Rong Zhang for their careful reading of the manuscript and for their constructive advice. They also thank ESSIC for supporting the publication of this paper.

\footnotetext{
${ }^{13}$ The 12-yr lead in Figs. 10 and 11 is discussed but not the 19-yr one. The lead-lag correlations of the PCs are similar to those of the indices but for notable differences when $t<-12 \mathrm{yr}$; in particular, the PCs do not support the indices-based finding of a 19-yr lead of AMO's negative phase over the PDO.
}

Data availability statement: All datasets analyzed in this study (sea surface temperature, sea level pressure, subsurface temperature and salinity, and climate indices) are publicly available through online data archives noted in their citation. The fishery data are obtained from published papers, all referenced. The analysis output, especially the sea surface temperature principal components which are the analysis fulcrum, are made available to the research community via the University of Maryland web link http://dsrs.atmos.umd.edu/DATA/pcs_glsst/.

\section{APPENDIX}

\section{Mature Phase Structure and Atmospheric Extensions of the SST Variability Modes}

The mature-phase structure of the SST variability modes not displayed in the main section is shown in Fig. A1. Upper-air extensions of recurrent SST variability, obtained from regressions of the winter (December-February) and summer (June-August) 500-hPa geopotential height (from NCEP reanalysis) on the 11 SST principal components, are shown in Fig. A2.

\section{REFERENCES}

Alexander, M. A., I. Bladé, M. Newman, J. R. Lanzante, N.-C. Lau, and J. D. Scott, 2002: The atmospheric bridge: The influence of ENSO teleconnections on air-sea interaction over the global oceans. J. Climate, 15, 2205-2231, https:// doi.org/10.1175/1520-0442(2002)015<2205:TABTIO > 2.0.CO;2.

Allan, R., and T. Ansell, 2006: A new globally complete monthly historical gridded mean sea level pressure dataset (HadSLP2): 1850 2004. J. Climate, 19, 5816-5842, https://doi.org/10.1175/ JCLI3937.1.

Álvarez-García, F., M. Latif, and A. Biastoch, 2008: On multidecadal and quasi-decadal North Atlantic variability. J. Climate, 21 3433-3452, https://doi.org/10.1175/2007JCLI1800.1.

Bader, J., and M. Latif, 2003: The impact of decadal-scale Indian Ocean sea surface temperature anomalies on Sahelian rainfall and the North Atlantic Oscillation. Geophys. Res. Lett., 30, 2169, https://doi.org/10.1029/2003GL018426.

Barlow, M., S. Nigam, and E. H. Berbery, 2001: ENSO, Pacific decadal variability, and U.S. summertime precipitation, drought, and stream flow. J. Climate, 14, 2105-2128, https://doi.org/10.1175/ 1520-0442(2001)014<2105:EPDVAU>2.0.CO;2.

Bjerknes, J., 1964: Atlantic air-sea interaction. Advances in Geophysics, Vol. 10, Elsevier, 1-82.

Bond, N. A., M. F. Cronin, H. Freeland, and N. Mantua, 2015: Causes and impacts of the 2014 warm anomaly in the NE Pacific. Geophys. Res. Lett., 42, 3414-3420, https://doi.org/ 10.1002/2015GL063306.

Booth, B. B., N. J. Dunstone, P. R. Halloran, T. Andrews, and N. Bellouin, 2012: Aerosols implicated as a prime driver of twentieth-century North Atlantic climate variability. Nature, 484, 228-232, https://doi.org/10.1038/nature10946. 
Chafik, L., S. Häkkinen, M. H. England, J. A. Carton, S. Nigam, A. Ruiz-Barradas, A. Hannachi, and L. Miller, 2016: Global linkages originating from decadal oceanic variability in the subpolar North Atlantic. Geophys. Res. Lett., 43, 10909 10 919, https://doi.org/10.1002/2016GL071134.

Chen, X., and J. M. Wallace, and K.-K. Tung, 2017: Pairwise-rotated EOFs of global SST. J. Climate, 30, 5473-5489, https:// doi.org/10.1175/JCLI-D-16-0786.1.

Chikamoto, Y., M. Kimoto, M. Watanabe, M. Ishii, and T. Mochizuki, 2012: Relationship between the Pacific and Atlantic stepwise climate change during the 1990s. Geophys. Res. Lett., 39, L21710, https://doi.org/10.1029/2012GL053901.

Chung, C., S. Nigam, and J. A. Carton, 2002: SST-forced surface wind variability in the tropical Atlantic: An empirical model. J. Geophys. Res., 107, 4244, https://doi.org/10.1029/ 2001JD000324.

Clement, A., K. Bellomo, L. N. Murphy, M. A. Cane, T. Mauritsen, G. Rädel, and B. Stevens, 2015: The Atlantic Multidecadal Oscillation without a role for ocean circulation. Science, $\mathbf{3 5 0}$, 320-324, https://doi.org/10.1126/science.aab3980.

Cleveland, W. S., and C. L. Loader, 1996: Smoothing by local regression: Principles and methods. Statistical Theory and Computational Aspects of Smoothing, W. Haerdle and M. G. Schimek, Eds., Springer, 10-49.

Czaja, A., A. Robertson, and T. Huck, 2003: The role of coupled processes in producing NAO variability. North Atlantic Oscillation Climatic Significance and Environmental Impact, Geophys. Monogr., No. 134, Amer. Geophys. Union, 147-172, https://doi.org/10.1029/134GM07.

de Coetlogon, G., and C. Frankignoul, 2003: On the persistence of winter sea surface temperature in the North Atlantic. J. Climate, 16, 1364-1377, https://doi.org/10.1175/1520-0442-16.9.1364.

Delworth, T., S. Manabe, and R. J. Stouffer, 1993: Interdecadal variations of the thermohaline circulation in a coupled ocean-atmosphere model. J. Climate, 6, 1993-2011, https:// doi.org/10.1175/1520-0442(1993)006<1993:IVOTTC>2.0.CO;2.

_ , F. Zeng, L. Zhang, R. Zhang, G. A. Vecchi, and X. Yang, 2017: The central role of ocean dynamics in connecting the North Atlantic Oscillation to the extratropical component of the Atlantic Multidecadal Oscillation. J. Climate, 30, 37893805, https://doi.org/10.1175/JCLI-D-16-0358.1.

Deser, C., and M. Blackmon, 1995: On the relationship between tropical and North Pacific sea surface temperature variations. J. Climate, 8, 1677-1680, https://doi.org/10.1175/1520-0442(1995) 008<1677:OTRBTA $>2.0 . \mathrm{CO} ; 2$.

_- M. Alexander, and M. Timlin, 2003: Understanding the persistence of sea surface temperature anomalies in midlatitudes. J. Climate, 16, 57-72, https://doi.org/10.1175/15200442(2003)016<0057:UTPOSS > 2.0.CO;2.

_ A. S. Phillips, and J. W. Hurrell, 2004: Pacific interdecadal climate variability: Linkages between the tropics and the North Pacific during boreal winter since 1900. J. Climate, 17, 3109-3124, https://doi.org/10.1175/1520-0442(2004)017<3109: PICVLB $>2.0 . \mathrm{CO} ; 2$

_ M. Alexander, S. Xie, and A. Phillips, 2010: Sea surface temperature variability: Patterns and mechanisms. Annu. Rev. Mar. Sci., 2, 115-143, https://doi.org/10.1146/annurev-marine120408-151453.

Di Lorenzo, E., 2019: NPGO Index, http://www.o3d.org/npgo/ npgo.php.

_ ocean climate and ecosystem change. Geophys. Res. Lett., 35, L08607, https://doi.org/10.1029/2007GL032838.
d'Orgeville, M., and W. R. Peltier, 2007: On the Pacific Decadal Oscillation and the Atlantic Multidecadal Oscillation: Might they be related? Geophys. Res. Lett., 34, L23705, https:// doi.org/10.1029/2007GL031584.

Drews, A., and R. J. Greatbatch, 2016: Atlantic multidecadal variability in a model with an improved North Atlantic current. Geophys. Res. Lett., 43, 8199-8206, https://doi.org/ 10.1002/2016GL069815.

Enfield, D. B., and D. A. Mayer, 1997: Tropical Atlantic sea surface temperature variability and its relation to El Niño-Southern Oscillation. J. Geophys. Res., 102, 929-945, https://doi.org/ 10.1029/96JC03296.

, and A. M. Mestas-Nuñez, 1999: Multiscale variabilities in global sea surface temperatures and their relationships with tropospheric climate patterns. J. Climate, 12, 2719-2733, https://doi.org/10.1175/1520-0442(1999)012<2719:MVIGSS> 2.0.CO;2.

-, , and P. J. Trimble, 2001: The Atlantic Multidecadal Oscillation and its relation to rainfall and river flows in the continental US. Geophys. Res. Lett., 28, 2077-2080, https:// doi.org/10.1029/2000GL012745.

Folland, C. K., T. N. Palmer, and D. E. Parker, 1986: Sahel rainfall and worldwide sea temperatures, 1901-85. Nature, 320, 602607, https://doi.org/10.1038/320602a0.

Frankignoul, C., and K. Hasselmann, 1977: Stochastic climate models, Part II. Application to sea-surface temperature anomalies and thermocline variability. Tellus, 29, 289-305, https://doi.org/10.3402/tellusa.v29i4.11362.

Gastineau, G., and C. Frankignoul, 2015: Influence of the North Atlantic SST variability on the atmospheric circulation during the twentieth century. J. Climate, 28, 1396-1416, https:// doi.org/10.1175/JCLI-D-14-00424.1.

Giannini, A., R. Saravanan, and P. Chang, 2003: Oceanic forcing of Sahel rainfall on interannual to interdecadal time scales. Science, 302, 1027-1030, https://doi.org/10.1126/science.1089357.

Good, S. A., M. J. Martin, and N. A. Rayner, 2013: EN4: Quality controlled ocean temperature and salinity profiles and monthly objective analyses with uncertainty estimates. J. Geophys. Res. Oceans, 118, 6704-6716, https://doi.org/ 10.1002/2013JC009067.

Guan, B., and S. Nigam, 2008: Pacific sea surface temperatures in the twentieth century: An evolution-centric analysis of variability and trend. J. Climate, 21, 2790-2809, https://doi.org/ 10.1175/2007JCLI2076.1.

_ and _ 2009: Analysis of Atlantic SST variability factoring interbasin links and the secular trend: Clarified structure of the Atlantic Multidecadal Oscillation. J. Climate, 22, 4228-4240, https://doi.org/10.1175/2009JCLI2921.1.

Ham, Y.-G., J.-S. Kug, J.-Y. Park, and F.-F. Jin, 2013: Sea surface temperature in the north tropical Atlantic as a trigger for El Niño/Southern Oscillation events. Nat. Geosci., 6, 112-116, https://doi.org/10.1038/ngeo1686.

Hameed, S., K. R. Sperber, and A. Meinster, 1993: Teleconnections of the Southern Oscillation in the tropical Atlantic sector in the OSU coupled upper ocean-atmosphere GCM. J. Climate, 6, 487-498, https://doi.org/10.1175/1520-0442(1993)006<0487: TOTSOI $>2.0 . \mathrm{CO} ; 2$.

Hare, S. R., and N. J. Mantua, 2000: Empirical evidence for North Pacific regime shifts in 1977 and 1989. Prog. Oceanogr., 47, 103-145, https://doi.org/10.1016/S0079-6611(00)00033-1.

Hoerling, M. P., J. W. Hurrell, and T. Xu, 2001: Tropical origins for recent North Atlantic climate change. Science, 292, 90-92, https://doi.org/10.1126/science.1058582. 
Hurrell, J. W., 1995: Decadal trends in the North Atlantic Oscillation: Regional temperatures and precipitation. Science, 269, 676-679, https://doi.org/10.1126/science.269.5224.676.

—, Y. Kushnir, G. Ottersen, and M. Visbeck, 2003: An overview of the North Atlantic Oscillation. The North Atlantic Oscillation: Climatic Significance and Environmental Impact, Geophys. Monogr., No. 134, Amer. Geophys. Union, 1-35.

ICES, 2011: Report of the Working Group on Widely Distributed Stocks (WGWIDE). International Council for the Exploration of the Sea (ICES) CM 2011/ACOM:15, 642 pp., http://ices.dk/ sites/pub/Publication\%20Reports/Expert\%20Group\%20Report/ acom/2018/WGWIDE/01\%20WGWIDE\%20Report.pdf.

Joseph, R., and S. Nigam, 2006: ENSO evolution and teleconnections in IPCC's twentieth-century climate simulations: Realistic representation? J. Climate, 19, 4360-4377, https:// doi.org/10.1175/JCLI3846.1.

Joyce, T. M., C. Deser, and M. A. Spall, 2000: The relation between decadal variability of subtropical mode water and the North Atlantic Oscillation. J. Climate, 13, 2550-2569, https://doi.org/ 10.1175/1520-0442(2000)013<2550:TRBDVO>2.0.CO;2.

Kaiser, H. F., 1958: The Varimax criterion for analytic rotation in factor analysis. Psychometrika, 23, 187-200.

Kalnay, E., and Coauthors, 1996: The NCEP/NCAR 40-Year Reanalysis Project. Bull. Amer. Meteor. Soc., 77, 437-471, https:// doi.org/10.1175/1520-0477(1996)077<0437:TNYRP>2.0.CO;2.

Kavvada, A., A. Ruiz-Barradas, and S. Nigam, 2013: AMO's structure and climate footprint in observations and IPCC AR5 climate simulations. Climate Dyn., 41, 1345-1364, https:// doi.org/10.1007/s00382-013-1712-1.

Kawamura, R., 1994: A rotated EOF analysis of global sea surface temperature variability with interannual and interdecadal scales. J. Phys. Oceanogr., 24, 707-715, https://doi.org/10.1175/ 1520-0485(1994)024<0707:AREAOG >2.0.CO;2.

Knight, J. R., R. J. Allan, C. K. Folland, M. Vellinga, and M. E. Mann, 2005: A signature of persistent natural thermohaline circulation cycles in observed climate. Geophys. Res. Lett., 32, L20708, https://doi.org/10.1029/2005GL024233.

Kong, T. M., H. L. Gilroy, and R. C. Leickly, 2004: Definition of IPHC statistical areas. International Pacific Halibut Commission, https://iphc.int/uploads/pdf/tr/IPHC-2004-TR049.pdf.

Latif, M., and N. S. Keenlyside, 2011: A perspective on decadal climate variability and predictability. Deep-Sea Res. II, 58, 1880-1894, https://doi.org/10.1016/j.dsr2.2010.10.066.

Levitus, S., J. I. Antonov, T. P. Boyer, R. A. Locarnini, H. E. Garcia, and A. V. Mishonov, 2009: Global ocean heat content 1955-2008 in light of recently revealed instrumentation problems. Geophys. Res. Lett., 36, L07608, https://doi.org/10.1029/ 2008GL037155.

Li, J.-P., C. Sun, and F.-F. Jin, 2013: NAO implicated as a predictor of Northern Hemisphere mean temperature multidecadal variability. Geophys. Res. Lett., 40, 5497-5502, https://doi.org/ 10.1002/2013GL057877.

Li, X., S.-P. Xie, S. T. Gille, and C. Yoo, 2015: Atlantic-induced pantropical climate change over the past three decades. Nat. Climate Change, 6, 275-279, https://doi.org/10.1038/nclimate2840.

Liu, Z., and M. Alexander, 2007: Atmospheric bridge, oceanic tunnel, and global climatic teleconnections. Rev. Geophys., 45, RG2005, https://doi.org/10.1029/2005RG000172.

Mantua, N. J., S. R. Hare, Y. Zhang, J. M. Wallace, and R. C. Francis, 1997: A Pacific interdecadal climate oscillation with impacts on salmon production. Bull. Amer. Meteor. Soc., 78, 1069-1079, https://doi.org/10.1175/1520-0477(1997)078<1069: APICOW $>2.0 . \mathrm{CO} ; 2$.
Marini, C., and C. Frankignoul, 2014: An attempt to deconstruct the Atlantic Multidecadal Oscillation. Climate Dyn., 43, 607625, https://doi.org/10.1007/s00382-013-1852-3.

Marshall, J., and Coauthors, 2001: North Atlantic climate variability: Phenomena, impacts and mechanisms. Int. J. Climatol. J. Roy. Meteor. Soc., 21, 1863-1898, https://doi.org/10.1002/joc.693.

McCabe, G. J., and M. A. Palecki, 2006: Multidecadal climate variability of global lands and oceans. Int. J. Climatol., 26, 849865, https://doi.org/10.1002/joc.1289.

,-- , and J. L. Betancourt, 2004: Pacific and Atlantic Ocean influences on multidecadal drought frequency in the United States. Proc. Natl. Acad. Sci. USA, 101, 4136-4141, https:// doi.org/10.1073/pnas.0306738101.

McGregor, S., A. Timmermann, M. F. Stuecker, M. H. England, M. Merrifield, F.-F. Jin, and Y. Chikamoto, 2014: Recent Walker circulation strengthening and Pacific cooling amplified by Atlantic warming. Nat. Climate Change, 4, 888-892, https:// doi.org/10.1038/nclimate2330.

Messié, M., and F. Chavez, 2011: Global modes of sea surface temperature variability in relation to regional climate indices. J. Climate, 24, 4314-4331, https://doi.org/10.1175/ 2011JCLI3941.1.

Mestas-Nuñez, A. M., and D. B. Enfield, 1999: Rotated global modes of non-ENSO sea surface temperature variability. J. Climate, 12, 2734-2746, https://doi.org/10.1175/15200442(1999)012<2734:RGMONE > 2.0.CO;2.

Metz, W., 1991: Optimal relationship of large-scale flow patterns and the barotropic feedback due to high-frequency Eddies. J. Atmos. Sci., 48, 1141-1159, https://doi.org/10.1175/15200469(1991)048<1141:OROLSF $>2.0 . \mathrm{CO} ; 2$.

Namias, J., 1950: The index cycle and its role in the general circulation. J. Meteor., 7, 130-139, https://doi.org/10.1175/15200469(1950)007<0130:TICAIR >2.0.CO;2.

_ 1966: Nature and possible causes of the northeastern United States drought during 1962-65. Mon. Wea. Rev., 94, 543-554, https://doi.org/10.1175/1520-0493(1966)094<0543:NAPCOT $>$ 2.3.CO;2.

NEFSC, 1996: Report of the 20th Northeast Regional Stock Assessment Workshop (20th SAW): Stock Assessment Review Committee (SARC) consensus summary of assessments. Northeast Fish. Sci. Cent. Ref. Doc. 95-18. 211 pp.

, 2006: 42nd Northeast Regional Stock Assessment Workshop (42nd SAW) stock assessment report, part A: Silver hake, Atlantic mackerel, and northern shortfin squid (CRD 06-09a). U.S. Department of Commerce, Northeast Fish. Sci. Cent. Ref. Doc. 06-09a; 284 pp.

__ 2018: 64th Northeast Regional Stock Assessment Workshop (64th SAW) Assessment Summary Report. U.S. Department of Commerce, Northeast Fish. Sci. Cent. Ref. Doc. 18-03; 27 pp.

Nigam, S., 2003: Teleconnections. Encyclopedia of Atmospheric Sciences, Academic Press, 2243-2269.

_ atmosphere annual cycle variability. J. Climate, 9, 3187-3205, https://doi.org/10.1175/1520-0442(1996)009<3187:EDOTOA $>$ 2.0.CO;2.

_ - and A. Ruiz-Barradas, 2016: Key role of the Atlantic multidecadal oscillation in twentieth century drought and wet periods over the US Great Plains and the Sahel. Dynamics and Predictability of Large-Scale, High-Impact Weather and Climate Events, J. Li et al., Eds., Cambridge University Press, 255-270.

, M. Barlow, and E. H. Berbery, 1999: Analysis links Pacific decadal variability to drought and streamflow in United States. 
Eos, Trans. Amer. Geophys. Union, 80, 621-625, https://doi.org/ 10.1029/99EO00412.

- B. Guan, and A. Ruiz-Barradas, 2011: Key role of the Atlantic multidecadal oscillation in 20th century drought and wet periods over the Great Plains. Geophys. Res. Lett., 38, L16713, https://doi.org/10.1029/2011GL048650.

— , A. Ruiz-Barradas, and L. Chafik, 2018: Gulf Stream excursions and sectional detachments generate the decadal pulses in the Atlantic Multidecadal Oscillation. J. Climate, 31, 2853 2870, https://doi.org/10.1175/JCLI-D-17-0010.1.

O'Reilly, C. H., M. Huber, T. Woollings, and L. Zanna, 2016: The signature of low-frequency oceanic forcing in the Atlantic Multidecadal Oscillation. Geophys. Res. Lett., 43, 2810-2818, https://doi.org/10.1002/2016GL067925.

Palmer, M. C., 2014: Assessment update report of the Gulf of Maine Atlantic cod stock. US Department of Commerce, NEFSC Doc. 14-14, 119 pp.

Rasmusson, E. M., and T. H. Carpenter, 1983: The relationship between eastern equatorial Pacific sea surface temperatures and rainfall over India and Sri Lanka. Mon. Wea. Rev., 111 517-528, https://doi.org/10.1175/1520-0493(1983)111<0517: TRBEEP $>2.0 . \mathrm{CO} ; 2$.

Rayner, N. A., D. E. Parker, E. B. Horton, C. K. Folland, L. V. Alexander, D. P. Rowell, E. C. Kent, and A. Kaplan, 2003: Global analyses of sea surface temperature, sea ice, and night marine air temperature since the late nineteenth century. J. Geophys. Res., 108, 4407, https://doi.org/10.1029/2002JD002670.

Richman, M. B., 1986: Rotation of principal components. J. Climatol., 6, 293-335, https://doi.org/10.1002/joc.3370060305.

Rogers, J. C., 1984: The association between the North Atlantic Oscillation and the Southern Oscillation in the Northern Hemisphere. Mon. Wea. Rev., 112, 1999-2015, https://doi.org/ 10.1175/1520-0493(1984)112<1999:TABTNA > 2.0.CO;2.

Ropelewski, C. F., and M. S. Halpert, 1987: Global and regional scale precipitation patterns associated with the El Niño/ Southern Oscillation. Mon. Wea. Rev., 115, 1606-1626, https:// doi.org/10.1175/1520-0493(1987)115<1606:GARSPP>2.0.CO;2.

Ruiz-Barradas, A., and S. Nigam, 2005: Warm season rainfall variability over the US Great Plains in observations, NCEP and ERA-40 reanalyses, and NCAR and NASA atmospheric model simulations. J. Climate, 18, 1808-1830, https://doi.org/ 10.1175/JCLI3343.1.

_ J. A. Carton, and S. Nigam, 2000: Structure of interannual-todecadal climate variability in the tropical Atlantic sector. J. Climate, 13, 3285-3297, https://doi.org/10.1175/1520-0442(2000) $013<3285$ :SOITDC $>2.0$. CO 2 .

— S. Nigam, and A. Kavvada, 2013: The Atlantic Multidecadal Oscillation in twentieth century climate simulations: Uneven progress from CMIP3 to CMIP5. Climate Dyn., 41, 3301-3315, https://doi.org/10.1007/s00382-013-1810-0.

Seager, R., Y. Kushnir, C. Herweijer, N. Naik, and J. Velez, 2005: Modeling of tropical forcing of persistent droughts and pluvials over western North America: 1856-2000. J. Climate, 18, 4065-4088, https://doi.org/10.1175/JCLI3522.1.

SEDAR, 2015: SEDAR 40: Atlantic Menhaden Stock Assessment Report. Southeast Data Assessment and Review, 643 pp.

Stewart, I. J., and S. Martell, 2014: Assessment of the Pacific halibut stock at the end of 2014. IPHC Report of Assessment and Research Activities, 161-180, https://irma.nps.gov/Datastore/ DownloadFile/579222.
Sun, C., J.-P. Li, and F.-F. Jin, 2015: A delayed oscillator model for the quasi-periodic multidecadal variability of the NAO. Climate Dyn., 45, 2083-2099, https://doi.org/10.1007/s00382-014-2459-z.

— , F. Kucharski, J.-P. Li, F.-F. Jin, I. Kang, and R. Ding, 2017: Western tropical Pacific multidecadal variability forced by the Atlantic Multidecadal Oscillation. Nat. Commun., 8, 15998, https://doi.org/10.1038/ncomms15998.

Thomas, N., and S. Nigam, 2018: Twentieth-century climate change over Africa: Seasonal hydroclimate trends and Sahara Desert expansion. J. Climate, 31, 3349-3370, https://doi.org/10.1175/ JCLI-D-17-0187.1.

Ting, M., and H. Wang, 1997: Summertime US precipitation variability and its relation to Pacific sea surface temperature. J. Climate, 10, 1853-1873, https://doi.org/10.1175/1520-0442(1997) $010<1853$ :SUSPVA $>2.0$. CO 2

Toresen, R., and O. J. Østvedt, 2000: Variation in abundance of Norwegian spring-spawning herring (Clupea harengus, Clupeidae) throughout the 20th century and the influence of climatic fluctuations. Fish Fish., 1, 231-256, https://doi.org/10.1046/ j.1467-2979.2000.00022.x.

Wang, C., 2006: An overlooked feature of tropical climate: InterPacific-Atlantic variability. Geophys. Res. Lett., 33, L12702, https://doi.org/10.1029/2006GL026324.

Weare, B. C., and J. S. Nasstrom, 1982: Examples of extended empirical orthogonal function analyses. Mon. Wea. Rev., 110, 481-485, https://doi.org/10.1175/1520-0493(1982)110<0481: EOEEOF $>2.0 . \mathrm{CO} ; 2$.

Wu, S., Z. Liu, R. Zhang, and T. Delworth, 2011: On the observed relationship between the Pacific decadal oscillation and the Atlantic Multi-decadal Oscillation. J. Oceanogr., 67, 27-35, https://doi.org/10.1007/s10872-011-0003-x.

Yasunaka, S., and K. Hanawa, 2005: Regime shift in the global seasurface temperatures: Its relation to El Niño-Southern Oscillation events and dominant variation modes. Int. J. Climatol., 25, 913-930, https://doi.org/10.1002/joc.1172.

Zhang, R., 2017: On the persistence and coherence of subpolar sea surface temperature and salinity anomalies associated with the Atlantic multidecadal variability. Geophys. Res. Lett., 44, 7865-7875, https://doi.org/10.1002/ 2017GL074342.

— Oscillations on India/Sahel rainfall and Atlantic hurricanes. Geophys. Res. Lett., 33, L17712, https://doi.org/10.1029/ 2006 GL026267.

_- , and G. K. Vallis, 2006: Impact of great salinity anomalies on the low-frequency variability of the North Atlantic climate. J. Climate, 19, 470-482, https://doi.org/10.1175/ JCLI3623.1.

, and T. L. Delworth, 2007: Impact of the Atlantic Multidecadal Oscillation on North Pacific climate variability. Geophys. Res. Lett., 34, L23708, https://doi.org/10.1029/2007GL031601.

, and Coauthors, 2013: Have aerosols caused the observed Atlantic multidecadal variability? J. Atmos. Sci., 70, 11351144, https://doi.org/10.1175/JAS-D-12-0331.1.

R. Sutton, G. Danabasoglu, T. L. Delworth, W. M. Kim, J. Robson, and S. G. Yeager, 2016: Comment on "The Atlantic Multidecadal Oscillation without a role for ocean circulation." Science, 352, 1527-1527, https://doi.org/10.1126/ science.aaf1660. 